\title{
Nitric Oxide Signaling Strengthens Inhibitory Synapses of Cerebellar Molecular Layer Interneurons through a GABARAP-Dependent Mechanism
}

\author{
Erik A. Larson, ${ }^{1,3}$ Michael V. Accardi, ${ }^{2,3}$ Ying Wang, ${ }^{4,5,6}$ Martina D’Antoni, ${ }^{1,3}$ Benyamin Karimi, ${ }^{4,5,6}$ \\ Tabrez J. Siddiqui, ${ }^{4,5,6}$ and ${ }^{(D)}$ Derek Bowie $^{3}$ \\ ${ }^{1}$ Integrated Program in Neuroscience, McGill University, Montréal, Québec, Canada H3A 2B4, ${ }^{2}$ Graduate Program in Pharmacology, McGill \\ University, Montréal, Québec, Canada H3G 1Y6, ${ }^{3}$ Department of Pharmacology and Therapeutics, McGill University, Montréal H3G 0B1, Québec, \\ Canada, ${ }^{4}$ Department of Physiology and Pathophysiology, Max Rady College of Medicine, Rady Faculty of Health Sciences, University of Manitoba, \\ Winnipeg, Manitoba, Canada R3E 0J9, ${ }^{5}$ Neuroscience Research Program, Kleysen Institute for Advanced Medicine, Health Sciences Centre, \\ Winnipeg, Manitoba, Canada R3E 3J7, and ${ }^{6}$ The Children's Hospital Research Institute of Manitoba, Winnipeg, Manitoba Canada R3E 3P4
}

Nitric oxide (NO) is an important signaling molecule that fulfills diverse functional roles as a neurotransmitter or diffusible second messenger in the developing and adult CNS. Although the impact of NO on different behaviors such as movement, sleep, learning, and memory has been well documented, the identity of its molecular and cellular targets is still an area of ongoing investigation. Here, we identify a novel role for NO in strengthening inhibitory $\mathrm{GABA}_{\mathrm{A}}$ receptor-mediated transmission in molecular layer interneurons of the mouse cerebellum. NO levels are elevated by the activity of neuronal NO synthase (nNOS) following $\mathrm{Ca}^{2+}$ entry through extrasynaptic NMDA-type ionotropic glutamate receptors (NMDARs). NO activates protein kinase $\mathrm{G}$ with the subsequent production of cGMP, which prompts the stimulation of NADPH oxidase and protein kinase $\mathrm{C}(\mathrm{PKC})$. The activation of PKC promotes the selective strengthening of $\alpha 3$-containing $\mathrm{GABA}_{\mathrm{A}} \mathrm{Rs}$ synapses through a GABA receptor-associated protein-dependent mechanism. Given the widespread but cell type-specific expression of the NMDAR/ nNOS complex in the mammalian brain, our data suggest that NMDARs may uniquely strengthen inhibitory GABAergic transmission in these cells through a novel NO-mediated pathway.

Key words: cerebellum; electrophysiology; GABA receptor; GABARAP; inhibitory synapse; plasticity

Significance Statement

Long-term changes in the efficacy of GABAergic transmission is mediated by multiple presynaptic and postsynaptic mechanisms. A prominent pathway involves crosstalk between excitatory and inhibitory synapses whereby $\mathrm{Ca}^{2+}$-entering through postsynaptic NMDARs promotes the recruitment and strengthening of $\mathrm{GABA}_{\mathrm{A}}$ receptor synapses via Ca ${ }^{2+} / \mathrm{calmodulin} \mathrm{de}-$ pendent protein kinase II. Although $\mathrm{Ca}^{2+}$ transport by NMDARs is also tightly coupled to nNOS activity and NO production, it has yet to be determined whether this pathway affects inhibitory synapses. Here, we show that activation of NMDARs trigger a NO-dependent pathway that strengthens inhibitory GABAergic synapses of cerebellar molecular layer interneurons. Given the widespread expression of NMDARs and nNOS in the mammalian brain, we speculate that NO control of GABAergic synapse efficacy may be more widespread than has been appreciated.

Received Sep. 12, 2019; revised Jan. 13, 2020; accepted Mar. 3, 2020.

Author contributions: E.A.L., M.V.A., T.J.S., and D.B. designed research; E.A.L., M.V.A., Y.W., M.D., and B.K. performed research; E.A.L., M.V.A., Y.W., M.D., B.K., T.J.S., and D.B. analyzed data; E.A.L., T.J.S., and D.B. wrote the paper.

This work was supported by Canadian Institutes of Health Research Operating Grants CIHR MOP-342247 to D.B. and by CIHR MOP-142209 to T.J.S. We thank members of the Bowie laboratory for discussions and comments on the paper.

The authors declare no competing financial interests.

Correspondence should be addressed to Derek Bowie at derek.bowie@mcgill.ca.

https://doi.org/10.1523/JNEUROSCI.2211-19.2020

Copyright $\odot 2020$ the authors

\section{Introduction}

The NMDA receptor (NMDAR) is an abundant neurotransmitter-gated ion-channel that orchestrates the formation, maintenance, and plasticity of almost all glutamatergic synapses in the developing and adult brain (Hardingham and Bading, 2003; Paoletti et al., 2013). It is implicated in numerous neurologic diseases from neurodevelopmental disorders (Bello et al., 2013; Hu et al., 2016) to neurodegenerative disease including Huntington's (Milnerwood and Raymond, 2010) and Alzheimer's disease (Liu et al., 2019). Two synergistic features of the NMDAR critical for its role in synaptic signaling are its slow channel gating (Glasgow 
et al., 2015) and high $\mathrm{Ca}^{2+}$ permeability (Gnegy, 2000). These properties of the NMDAR act together to ensure that the presynaptic release of L-glutamate elevates postsynaptic $\mathrm{Ca}^{2+}$ and triggers a cascade of $\mathrm{Ca}^{2+}$-dependent biochemical events inside the cell. Much of the activity initiated by NMDARs is relayed through the actions of $\mathrm{Ca}^{2+} /$ calmodulin-dependent protein kinase II (CaMKII; Sanhueza and Lisman, 2013), which is anchored to the NMDAR (Bayer et al., 2006) and thus ideally suited to act as a signaling hub. For example, it has been shown that this pathway originating at glutamatergic synapses strengthens GABAergic synapses (Marsden et al., 2007; Petrini et al., 2014; Chiu et al., 2018).

NMDA receptor signaling is also tightly coupled to neuronal nitric oxide synthase (nNOS) activity through the postsynaptic scaffold of PSD-95 and -93 (Brenman et al., 1996a,b). By elevating cytosolic $\mathrm{Ca}^{2+}$, synaptic NMDARs activate nNOS generating nitric oxide (NO), which has a variety of roles in neuronal communication and blood vessel modulation (Bredt, 1999; Kiss and Vizi, 2001). Accordingly, NO participates in numerous CNS functions including learning and memory, sleep and feeding behavior, movement, pain, anxiety, and reproductive activity (Garthwaite, 2019). An area of ongoing investigation is to identify the molecular and cellular targets of NO. What is known is that physiological levels of NO elevated by NMDAR stimulation act as a retrograde signal (Garthwaite, 2016), stimulate gene expression (Lu et al., 1999) and/or promote AMPA receptor (AMPAR) trafficking (Serulle et al., 2007). Conversely, excessive levels of NO promote neurotoxicity (Brown, 2010).

Here, we identify a new role for $\mathrm{NO}$ in strengthening GABAergic synapses of cerebellar molecular layer inhibitory neurons. We show that an elevation in cytosolic $\mathrm{Ca}^{2+}$ mediated by NMDARs triggers a cascade of signaling events that begin with nNOS activation and release of NO, which through the generation of cGMP activates protein kinase $\mathrm{G}(\mathrm{PKG})$. This pathway stimulates NADPH oxidase and protein kinase $\mathrm{C}$ (PKC) to strengthen $\alpha 3$-containing $\mathrm{GABA}_{\mathrm{A}}$ receptor $\left(\mathrm{GABA}_{\mathrm{A}} \mathrm{R}\right)$ synapses through a GABA receptor-associated protein (GABARAP)-dependent mechanism. Given the widespread but cell-type-specific expression of the NMDAR/nNOS complex in the mammalian CNS, our data suggest that NMDARs may uniquely strengthen inhibitory GABAergic transmission through a novel NO-mediated pathway in cerebellar molecular layer interneurons (MLIs) and other nNOS-positive $\left(\mathrm{nNOS}^{+}\right)$neurons.

\section{Materials and Methods}

\section{Animals}

Wild-type mice with a C57BL/6 background were obtained from Charles River Laboratories and maintained as a breeding colony at McGill University. Mice (male and female) used for the experiments ranged from 18 to $30 \mathrm{~d}$ old. All experiments have been approved and were performed in accordance with the guidelines of the Canadian Council on Animal Care and were approved by the Animal Care Committee of McGill University. Breeder pairs of Gabra3 KO (1-Gabra3tm2Uru/Uru), C57BL/6 background, were kindly provided by Dr. Rudolph (Harvard Medical School, McLean Hospital; Yee et al., 2005).

\section{Cerebellum slice preparation}

Mice were anaesthetized with isoflurane and immediately decapitated. The cerebellum was rapidly removed from the whole brain while submerged in oxygenated $\left(95 \% \mathrm{O}_{2}, 5 \% \mathrm{CO}_{2}\right)$ ice-cold cutting solution, which contained the following (in $\mathrm{mM}$ ): 235 sucrose, $2.5 \mathrm{KCl}, 1.25$ $\mathrm{NaH}_{2} \mathrm{PO}_{4}, 28 \mathrm{NaHCO}_{3}, 0.5 \mathrm{CaCl}_{2}, 7 \mathrm{MgSO}_{4}, 28$ D-glucose, pH 7.4, 305$315 \mathrm{mOsm} / \mathrm{L}$. The tissue was maintained in ice-cold solution while sagittal slices of cerebellar vermis $(300 \mu \mathrm{m})$ were cut using a vibrating tissue slicer (Leica VT1200, Leica Instruments). The slices were transferred to oxygenated artificial CSF (aCSF) and held at room temperature $\left(20-23^{\circ}\right.$ C) for at least $1 \mathrm{~h}$ before recordings were performed. aCSF contained the following (in mM): $125 \mathrm{NaCl}, 2.5 \mathrm{KCl}, 1.25 \mathrm{NaH}_{2} \mathrm{PO}_{4}, 26 \mathrm{NaHCO}_{3}, 2$ $\mathrm{CaCl}_{2}, 1 \mathrm{MgCl}_{2}, 25$ D-glucose, $\mathrm{pH}$ 7.4, 305-315 mOsm/L.

\section{Electrophysiology}

Slice experiments were performed on an Olympus BX51 upright microscope equipped with differential interference contrast/infrared optics. Whole-cell patch-clamp recordings were made from visually-identified MLIs, primarily in lobules IV and V, which were distinguished from misplaced or migrating granule cells by their soma diameter $(8-9 \mu \mathrm{m})$ and location in the molecular layer. For current-clamp experiments, patch pipettes were prepared from thick-walled borosilicate glass [GC150F-10, outer diameter (o.d.): $1.5 \mathrm{~mm}$, inner diameter (i.d.): 0.86 $\mathrm{mm}$; Harvard Apparatus] and had open tip resistances of 4-10 $\mathrm{M} \Omega$ when filled with an intracellular solution that contained the following (in mM): $126 \mathrm{~K}$-gluconate, $0.05 \mathrm{CaCl}_{2}, 0.15 \mathrm{~K}_{4} \mathrm{BAPTA}, 4 \mathrm{NaCl}, 1 \mathrm{MgSO}_{4}$, 5 HEPES, $3 \mathrm{Mg}$-ATP, $0.1 \mathrm{NaGTP}, 15$ D-glucose, 2 QX314 to block voltage-activated $\mathrm{Na}^{+}$channels, and $0.5 \mathrm{mg} / \mathrm{ml}$ Lucifer yellow as a post hoc dye indicator, $\mathrm{pH} 7.4$ with $\mathrm{KOH}, 300-310 \mathrm{mOsm} / \mathrm{L}$. High BAPTA intracellular current-clamp solution contained the following (in $\mathrm{mM}$ ): $110 \mathrm{~K}$ gluconate, $0.05 \mathrm{CaCl}_{2}, 10 \mathrm{~K}_{4} \mathrm{BAPTA}, 4 \mathrm{NaCl}, 5$ HEPES, $4 \mathrm{Mg}$-ATP, $0.1 \mathrm{NaGTP}, 15$ D-glucose, and $2 \mathrm{QX} 314, \mathrm{pH} 7.4$ with $\mathrm{KOH}, 300-310$ $\mathrm{mOsm} / \mathrm{L}$. Voltage-clamp recordings were made with patch pipettes prepared as described but filled with an intracellular solution that contained the following (in mM): $140 \mathrm{CsCl}, 4 \mathrm{NaCl}, 0.5 \mathrm{CaCl}_{2}, 10 \mathrm{HEPES}, 5 \mathrm{EGTA}$, $2 \mathrm{Mg}$-ATP, 2 QX314, pH 7.4 with CsOH, 300-310 mOsm/L. High BAPTA voltage-clamp solution contained $110 \mathrm{CsCl}, 4 \mathrm{NaCl}, 10$ HEPES, 10 $\mathrm{Cs}_{4}$ BAPTA, 2 Mg-ATP, 2 QX314, pH 7.4 with $\mathrm{CsOH}, 300-310$ mOsm/L. Specific $n$ numbers reported refer to technical replications (i.e., patchclamp recordings), while each experiment was replicated using at least three different mice.

In each case, recordings were made with a MultiClamp 700A amplifier (Molecular Devices) in voltage- or current-clamp mode. Series resistance and whole-cell capacitance were corrected and estimated by cancelling the fast current transients evoked at the onset and offset of brief (10-20 ms) $5 \mathrm{mV}$ voltage-command steps. Series resistance during postsynaptic whole-cell recording $(10-25 \mathrm{M} \Omega)$ was checked for stability throughout the experiments ( $<20 \%$ drift tolerance). The capacitance of the MLIs was in the range of $5-14 \mathrm{pF}$. The bath was continuously perfused at room temperature $\left(22-23^{\circ} \mathrm{C}\right)$ with aCSF at a rate of $1-2 \mathrm{ml} / \mathrm{min}$. We chose to perform recordings at room temperature rather than physiological temperature because it tended to increase the viability of the slice tissue and slowed the time course of synaptic events making them easier to resolve. Membrane currents were filtered at $5 \mathrm{kHz}$ with an 8 pole low-pass Bessel filter (Frequency Devices) and digitized at $25 \mathrm{kHz}$ with a Digidata 1322A data acquisition board and Clampex9 (Molecular Devices) software. Curve fitting and figure preparation of all electrophysiology data were performed using Origin 7.0 (OriginLab), Microsoft Excel, and Clampfit 10 (Molecular Devices) software.

For extracellular stimulation, thin walled borosilicate glass electrodes (o.d. $1.65 \mathrm{~mm}$, i.d. $1.15 \mathrm{~mm}$; King Precision Glass) were used with a tip resistance of $<3 \mathrm{M} \Omega$ when filled with aCSF. The ground electrode for the stimulation circuit was made with a platinum wire wrapped around the stimulation electrode. The stimulating electrode was positioned in the molecular layer at or just beneath the slice surface. Voltage pulses (10-25 V in amplitude, 200-400 $\mu$ s in duration) were applied at lowfrequency stimulation $(0.1 \mathrm{~Hz})$ through the stimulating electrode. To minimize variability between responses, the stimulating electrode was positioned $50-100 \mu \mathrm{m}$ away from the recorded cell. The stimulus voltage used during each experiment was at the lowest intensity to elicit the maximal evoked excitatory post synaptic potential/inhibitory post synaptic current (eEPSP/IPSC) response within the range described above. Stimulation strength and duration were kept constant throughout the experiment. For high-frequency stimulation (HFS), trains of six stimuli were delivered at $100 \mathrm{~Hz}$ (intertrain interval of $20 \mathrm{~s}$ ) as described previously (Li et al., 2011). This HFS protocol has been previously shown to generate reactive oxygen species 
(ROS; Li et al., 2011) and mimics somatosensory stimulation patterns (Jörntell and Ekerot, 2006; Saviane and Silver, 2006; Rancz et al., 2007; Arenz et al., 2008; Coddington et al., 2013). The HFS was performed every $5 \mathrm{~min}$ to ensure a continual accumulation of ROS. During the voltage-clamp experiments of evoked GABA currents (compare Fig. 2), we performed the HFS protocol at a holding potential of $+40 \mathrm{mV}$ to relieve $\mathrm{Mg}^{2+}$ block of NMDARs. We performed the single stimulation recordings at $-60 \mathrm{mV}$ to isolate the response from NMDA currents and used GYKI 53655 to pharmacologically block AMPA currents. For all experiments that included perfusion of either pharmacological or peptide blocker compounds in the internal solution we waited $15 \mathrm{~min}$ before beginning the HFS induction protocol. In experiments where the antioxidant $\mathrm{N}$-acetyl-cysteine (NAC) was included in the patch electrode solution, we unexpectedly observed that NAC alone increased the amplitude of baseline responses to $191.5 \% \pm 36(n=4)$ of the starting response, which stabilized $20 \mathrm{~min}$ after whole-cell breakthrough. Because this was not observed in the absence of NAC (Peak $\left.{ }_{15}: 100.2 \pm 5.5 \%, n=21\right)$, we concluded that the resting redox state of the cell affects the synaptic properties of MLIs. Antioxidants have been shown to potentiate both AMPARs (Lee et al., 2012) and NMDARs (Köhr et al., 1994). As our plasticity mechanism relies on NMDAR activation we would expect that any potentiating effect of NAC on the NMDAR current would be more likely to strengthen long term potentiation of inhibitory synapses (iLTP). Given this, HFS was commenced only after the effect of NAC on basal synaptic properties stabilized.

\section{Pharmacological compounds}

NMDAR antagonist, D-(-)-2-amino-5-phosphonopentanoic acid(D-APV; $10 \mu \mathrm{M})$, AMPA antagonist 1-(4-aminophenyl)-3-methylcarbamyl-4-methyl3,4-dihydro-7,8-methylenedioxy-5H-2,3-benzodiazepine hydrochloride (GYKI 53 655; $10 \mu \mathrm{M}$ ), and the $\mathrm{GABA}_{\mathrm{A}}$ Rs antagonist bicuculline (10 $\mu \mathrm{M})$ were purchased from Tocris Bioscience. Stock solutions of these antagonists were prepared in water and were stored at $-20^{\circ} \mathrm{C}$ and working solutions were diluted with aCSF shortly before application to the bath. NAC (1 mM; Sigma-Aldrich), protein kinase A (PKA) inhibitor fragment (6-22) amide (PKA 6-22; $5 \mu \mathrm{M}$; Tocris Bioscience), Ruthenium red (1 $\mu \mathrm{M}$; Tocris Bioscience), and cGMP analog pCPT-cGMP (10 $\mu \mathrm{M}$; Tocris Bioscience) were prepared as a stock solution in water and dissolved in patch electrode solution on the day of the experiment. Apocynin (Apo; $100 \mu \mathrm{M}$; Tocris Bioscience), 3-bromo-7-nitroindazole (3-Br-7-NI; $10 \mu \mathrm{M}$; Tocris Bioscience), KN-93 (5 $\mu \mathrm{M}$; Tocris Bioscience), Gö 6983 (5 $\mu \mathrm{M}$; Tocris Bioscience), phorbol 12-myristate 13-acetate (PMA; 100 nM; Tocris Bioscience), $1 \mathrm{H}$-[1,2,4] oxadiazolo[4,3-a]quinoxalin-1-one (ODQ; $10 \mu \mathrm{M}$; Tocris Bioscience), KT 5823 (5 $\mu \mathrm{m}$; Tocris Bioscience), and antimycin-A ( $2 \mu \mathrm{M}$; Sigma-Aldrich) were dissolved in DMSO and stored at $-20^{\circ} \mathrm{C}$. The $\mathrm{K} 1 \mathrm{GABARAP}, \mathrm{K} 1 \mathrm{GABARAP}$ scrambled, and $\alpha 3$-derived peptides (all $100 \mu \mathrm{M}$; Genscript) were dissolved in DMSO and stored at $-20^{\circ} \mathrm{C}$. The final maximum DMSO concentration for all experiments $(0.1 \% \mathrm{v} / \mathrm{v})$ had no effect on GABAergic responses, which was consistent with other studies (Nakahiro et al., 1992).

\section{cDNA constructs}

HA-GABAR- $\alpha 3$ contains the signal sequence of rat neuroligin 1 , the HA tag and mature sequence of rat GABAR- $\alpha 3$ (NM_017069) included in the Clontech EGFP-C1 vector. Human GABAR- $\beta 2$ (NM_000813) and human GABAR- $\gamma 2$ (NM_000816) were cloned into the pcDNA3 vector. Mouse GABARAP (BC030350) was C-terminally tagged with CFP in the Clontech ECFP-N1 vector. Rat gephyrin (NM_022865), N-terminally tagged with YFP, was cloned in the Clontech EYFP-C1 vector. All expression constructs were driven by the CMV promoter.

\section{Coimmunoprecipitation protocol}

Semi-confluent HEK 293 cells were plated on $60 \mathrm{~mm}$ dishes and transfected with YFP-Gephyrin, GABARAP-CFP or negative control YFP. Cotransfections were done with equivalent amounts of HA-GABAR- $\alpha 3$, GABAR- $\beta 2$, and GABAR- $\gamma 2$ (short). Cells were then allowed to grow for $24 \mathrm{~h}$ post-transfection. Protein-G Sepharose bead slurry $(50 \mu \mathrm{l})$ was incubated with $5 \mu \mathrm{g}$ of rat anti-HA antibody (3F10, Sigma-Aldrich) for 4 h at $4^{\circ} \mathrm{C}$. Cells were subsequently washed twice and collected in cold PBS. Harvested cells were lysed using $250 \mu \mathrm{l}$ of complexiolyte- 48 (Logopharm) and further disrupted by passaging 10-15 times through a $25 \mathrm{G}$ needle. Lysed cells were incubated at $4^{\circ} \mathrm{C}$ for $1 \mathrm{~h}$ on an end-over rotator. Subsequently, lysates were centrifuged at $14,000 \times g$ at $4^{\circ} \mathrm{C}$ for $10 \mathrm{~min}$. The resulting supernatants were incubated overnight at $4^{\circ} \mathrm{C}$ with Protein-G beads conjugated with anti-HA antibody. The beads were washed 3-4 times with complexiolyte-48 dilution buffer and eluted in $2 \times$ SDS-PAGE sample buffer. The resulting eluates along with $10 \mu \mathrm{l}$ of the supernatants used as expression control (input) were subjected to SDS-PAGE electrophoresis, immunoblotted on PVDF membranes, and probed with rabbit anti-GFP antibody (A11122, Life Technologies; 1:1000) followed by anti-rabbit HRP antibody (4030-05, Southern Biotech; 1:7000). The blots were developed using chemiluminescence in the ChemiDoc imaging system (Bio-Rad). For peptide interference experiments, the same protocol was followed with a third of the antibody, beads and lysates used. The scrambled GABARAP and GABARAP peptides were added to the lysates just before they were added to the beads with a final concentration $2.5 \mathrm{~mm}$.

\section{Statistical analysis}

Data were analyzed using SPSS (IBM) and custom statistical software kindly provided by Joe Rochford (McGill University). All data were tested for normality and appropriate parametric or nonparametric tests were conducted accordingly. For all repeated-measures ANOVA presented, Tukey's post hoc tests were conducted as indicated in the figure legends. For all Friedman tests, a Wilcoxon signed rank test with a Bonferroni-Holmes correction was conducted on the combinations. All statistical analysis of amplitudes (repeated-measures ANOVA or Friedman tests) were conducted comparing the baseline 5 min average of the datasets and each subsequent 5 min intervals following treatment up to 25 min posttreatment.

\section{Results}

\section{HFS of glutamatergic synapses strengthens inhibitory transmission}

To study activity-dependent plasticity of GABAergic synapses, we performed whole-cell current- and voltage-clamp electrophysiological recordings on cerebellar MLIs which receive synaptic input from both excitatory and inhibitory neurons (Fig. 1A). Current-clamp recordings were performed to examine the effect of GABAergic signaling on neuronal excitability whereas we used voltage-clamp recordings to study the $\mathrm{GABA}_{\mathrm{A}} \mathrm{R}$ response in isolation. Previous work from our laboratory has shown that GABAergic synapses of MLIs can be strengthened by elevating cytosolic ROS with the mitochondrial uncoupler, antimycin A (Accardi et al., 2014). It remains to be established, however, whether cytosolic ROS levels can be elevated by physiologically relevant stimuli, for example, through synaptic transmission. Because MLIs express extrasynaptic NMDARs (Clark and CullCandy, 2002), we reasoned that activation of these receptors by neurotransmitter spillover from glutamatergic fibers might elevate cytosolic ROS through a non-canonical signaling pathway that was previously described in cultured neurons (Dugan et al., 1995; Reynolds and Hastings, 1995).

To test this, we performed stimulation experiments of MLI glutamatergic synapses using a field-stimulating electrode placed in the molecular layer of the cerebellum to activate the parallel fiber axons from granule cells (Fig. 1A). Using this approach, two types of responses were observed in current-clamp recordings (Fig. $1 B, C$ ). In most of the recordings $(n=10)$, a single stimulation elicited a compound response composed of an initial EPSP that overlapped with an IPSP (Fig. 1B) suggesting that both excitatory parallel fiber-MLI (PF-MLI) synapses and inhibitory synapses had been stimulated. MLIs receive input from many inhibitory cells in the cerebellar cortex; therefore, the 

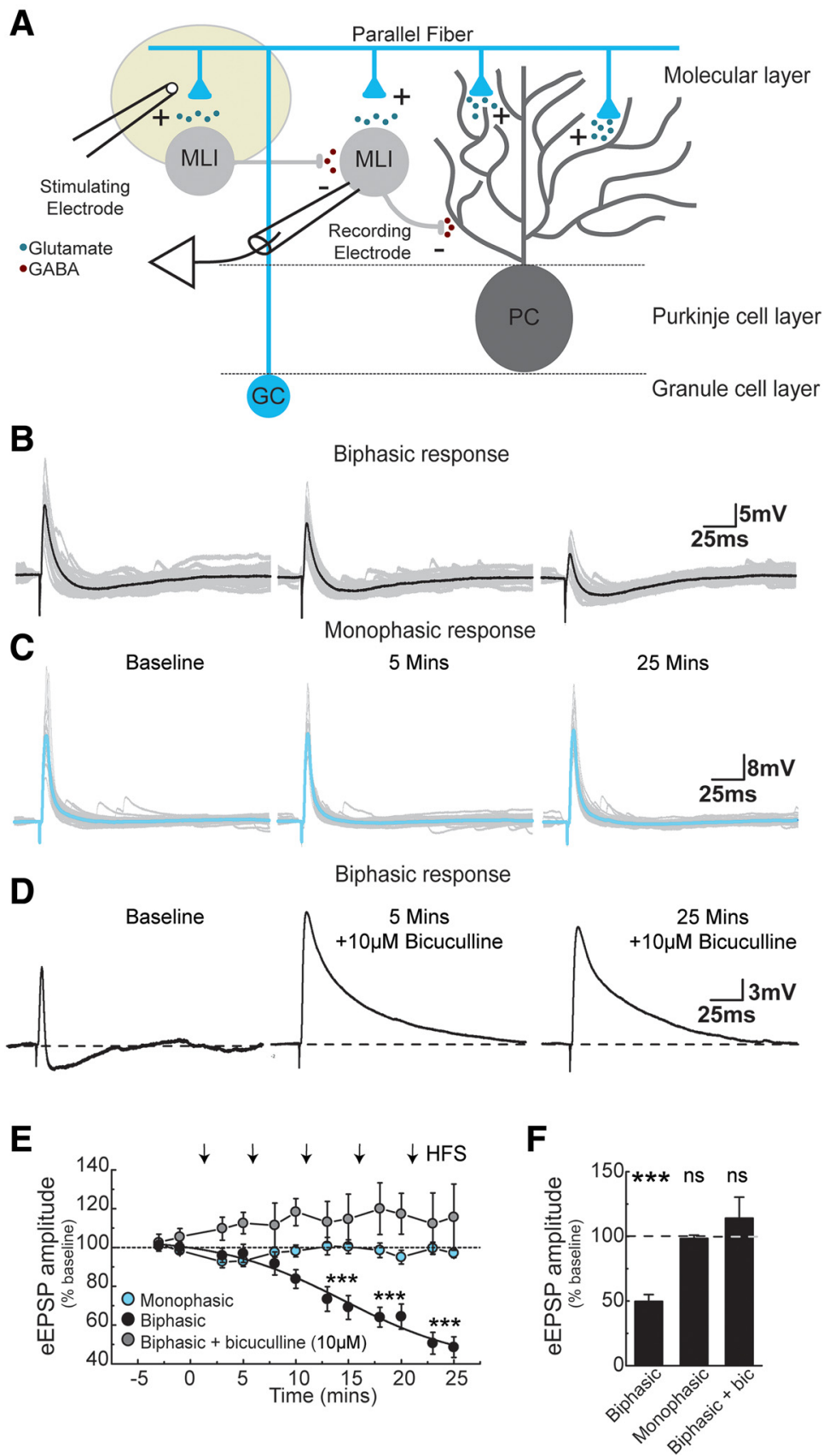

Figure 1. Repetitive stimulation of MLI excitatory synapses strengthens inhibitory neurotransmission. $A$, Schematic illustrating the arrangement of stimulating and recording electrodes. Stimulating electrode was positioned to focally depolarize (yellow circle) excitatory and inhibitory axons of cells innervating MLIs. PC, Purkinje cell; GC, granule cell. $\boldsymbol{B}, \boldsymbol{C}$, Representative current-clamp recordings from two MLIs with either a biphasic (B; cell 141105r2) or monophasic $(\boldsymbol{C} ;$ cell 141125 r3) response at three time points; before (baseline) and after (5 min or $25 \mathrm{~min}$ ) HFS. D. Representative current-clamp recordings from a MLI with a biphasic response at three time points; before (baseline) and $5 \mathrm{~min}$ after application of the $\mathrm{GABA}_{A} R s$ antagonist bicuculline and $25 \mathrm{~min}$ after HFS + bicuculline treatment (cell 150225r1). E, Time course plot of the eEPSP amplitude before and after HFS from monophasic $(n=7)$ or biphasic $(n=10)$ cells or biphasic cells in the presence of the bicuculline $(n=4)$. $\boldsymbol{F}$, Summary plot of the eEPSP amplitude at 25 min following HFS shown as a percentage of the initial baseline. Tukey's post hoc contrasts: ${ }^{* * *} p<0.001$. ns, not significant.

observed inhibitory signal could arise from the axons of adjacent MLIs and/or Lugaro and globular cells (Fritschy and Panzanelli, 2006). In other recordings $(n=8)$, field stimulation evoked a monophasic EPSP without any detectable hyperpolarization, suggesting that only PF-MLI excitatory synapses were activated (Fig. 1C).

To study GABAergic synapse plasticity, we adapted a HFS protocol used in other studies to elevate ROS (Li et al., 2011).
This HFS protocol is also in line with in vivo firing rates of cerebellar granule cells and the frequency of synaptic transmission for cerebellar MLIs (Chadderton et al., 2004). Using this protocol, a decline in the eEPSP amplitude was observed in recordings with a biphasic response over the 25 min following HFS (Peak $25: 48.6 \pm 5 \%$ of initial response, $n=10, F_{(5,45)}=34.55$, $p<0.00,001$, repeated-measures ANOVA; Fig. $1 B, E, F)$. In contrast, the EPSP amplitude was unchanged in cells exhibiting a monophasic response $\left(\right.$ Peak $_{25}: 98.3 \pm$ $2 \%, n=8, F_{(5,40)}=1.70, p=0.15$, repeatedmeasures ANOVA) suggesting that HFS did not directly affect the efficacy of glutamatergic transmission (Fig. $1 C, E, F$ ). We therefore reasoned that the decline elicited by HFS in cells with a biphasic response was due to a strengthening of inhibitory transmission. In agreement with this, application of $10 \mu \mathrm{M}$ bicuculline, to block $\mathrm{GABA}_{\mathrm{A}}$ Rs and the observed hyperpolarization, prevented the decline in the eEPSP amplitude (Peak $25: 115.6 \pm 17 \%, n=4$, $\chi_{(5)}^{2}=2.74, p=0.74$, Friedman test; Fig. 1D-F).

To better quantify the increase in GABAergic transmission, we performed the same HFS protocol in voltage-clamp mode and measured the evoked IPSCs (eIPSCs; Fig. 2). We observed a twofold increase in the eIPSC amplitude following the HFS protocol (HFS Peak 25 : 200.3 $\pm 35 \%$, $n=7, F_{(5,30)}=5.97, p=0.0006$, repeatedmeasures ANOVA), which was accompanied by a slowing in decay kinetics (Fig. $2 A-D$ ). This latter observation is consistent with our previous finding showing that elevation in ROS levels promotes the recruitment of $\alpha 3$ containing $\mathrm{GABA}_{\mathrm{A}} \mathrm{R}$ into inhibitory MLI synapses (Accardi et al., 2014). Potentiation was absent in experiments where the recorded cell did not receive HFS reaffirming that GABAergic transmission is stable under basal conditions (Control Peak 25 : $105.5 \pm 8 \%$, $n=8, \chi_{(5)}^{2}=2.67, p=0.75$, Friedman test). Furthermore, the potentiation of eIPSC amplitude was present only when the HFS protocol was paired with a depolarization to $+40 \mathrm{mV}$ and not when HFS was performed at $-60 \mathrm{mV}\left(\right.$ Peak $_{25}$ : $95.6 \pm 9 \%$, $n=6, \chi_{(5)}^{2}=0.57, p=0.98$, Friedman test; Fig. $\left.2 A-C\right)$. This latter finding suggests that the induction of long-term potentiation in GABAergic transmission (i.e., iLTP) may be postsynaptic and also involve an elevation in cytosolic $\mathrm{Ca}^{2+}$. In agreement with this, inclusion of $10 \mathrm{~mm}$ BAPTA, to chelate cytosolic $\mathrm{Ca}^{2+}$, eliminated the increase in eIPSC amplitude ( Peak $_{25}: 89 \pm 5 \%$, 
A
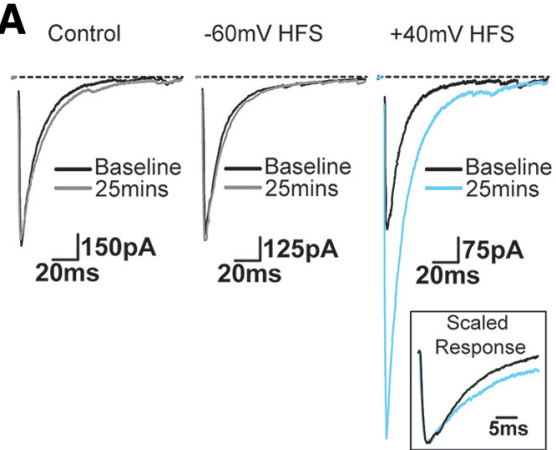

Treatment protocol:

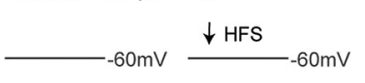

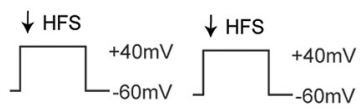

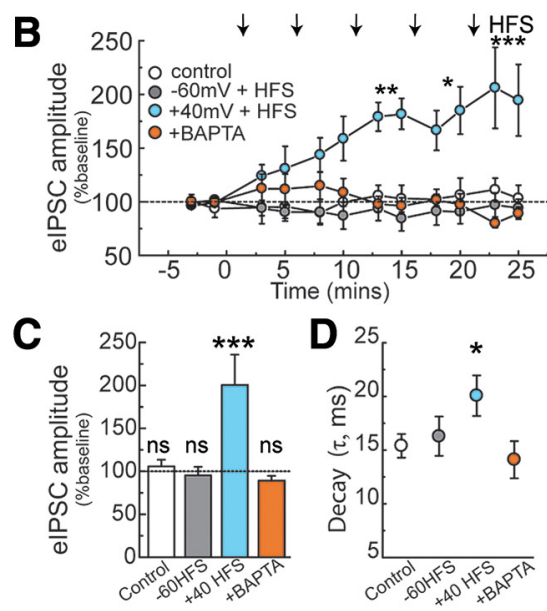

Figure 2. High-frequency stimulation evokes an increase in elPSC amplitude and a slowing of decay kinetics. $A$, GABA ${ }_{A} R$ currents from different MLIs just before the start (i.e., baseline) of the HFS protocol at $t=0$ min and after 25 min (cell numbers, Control: 160718r1, -60HFS: 171101r1, +40HFS: 160714r1, + BAPTA: 171019r1). Inset, Scaled response from the same trace as the +40 HFS demonstrating the slowing of decay kinetics following the HFS treatment. Stimulation artifacts have been removed for clarity. $\boldsymbol{B}$, Summary plot of the time course of elPSC amplitude during and following HFS expressed as a percentage of the baseline. $\boldsymbol{C}$, Summary bar graph of the elPSC amplitude observed in different experimental conditions at 25 min after HFS and expressed as a percentage of the baseline. D, Summary plot comparing the decay kinetics of eIPSCS at 25 min in different experimental conditions after HFS. Error bars indicate SEM. Tukey's post hoc contrasts: ${ }^{*} p<0.05,{ }^{* *} p<0.01,{ }^{* * *} p<0.001$. ns, not significant.
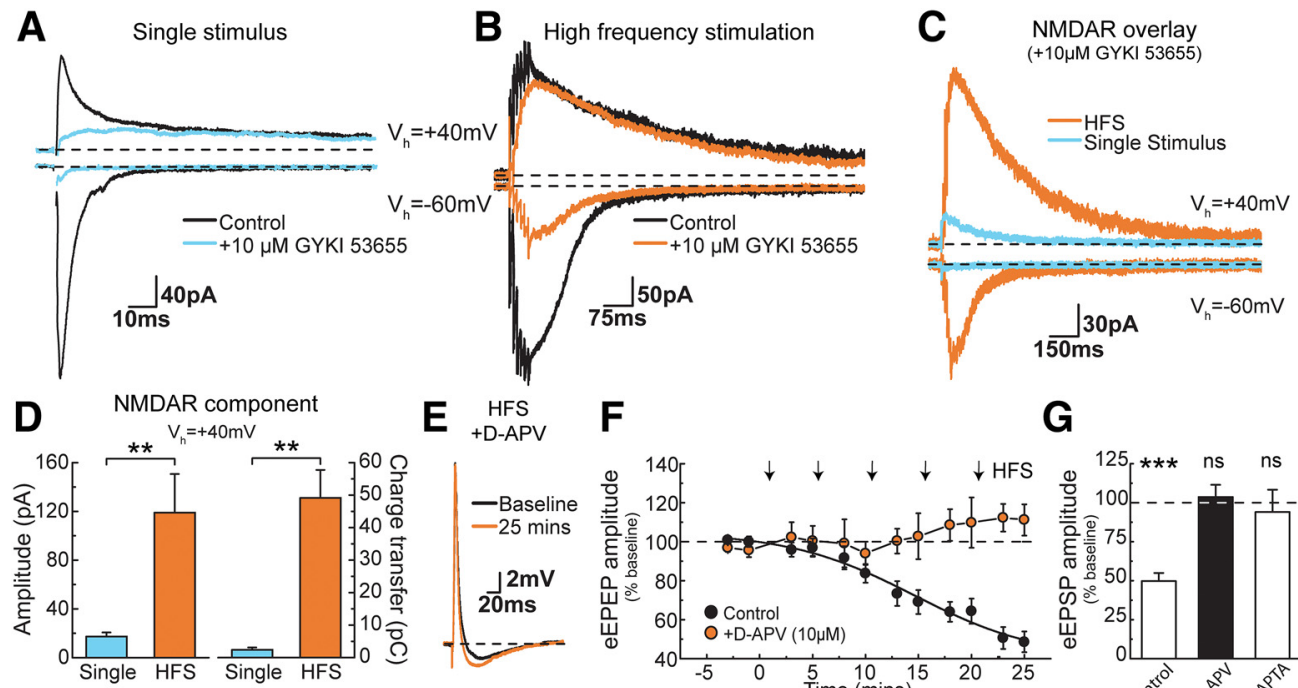

E $\begin{gathered}\text { HFS } \\ \text { +D-APV }\end{gathered}$

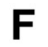

G
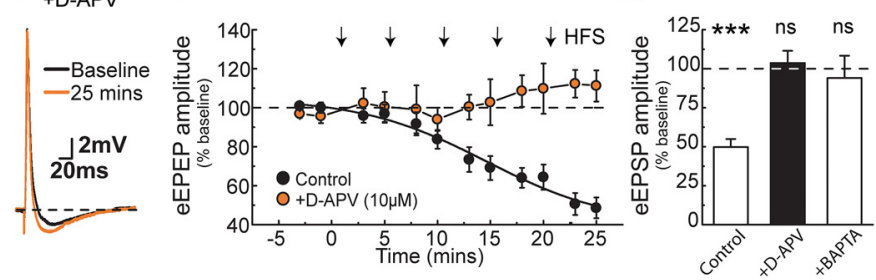

Figure 3. GABAergic synapses are strengthened by the activation of extrasynaptic NMDARs. $A$, Representative traces of evoked currents from a single stimulus at $+40 \mathrm{mV}$ (top) or $-60 \mathrm{mV}$ (bottom) membrane potential (cell 150317r1). Traces in blue or black denote responses observed in the presence or absence of the AMPAR antagonist, GYKI 53655 (10 $\mu \mathrm{m})$, respectively. $\boldsymbol{B}$, Representative traces of evoked currents (from the same cell as A) during a $100 \mathrm{~Hz} 6$ train stimulus (or HFS) at a membrane potential of $+40 \mathrm{mV}$ (top) and $-60 \mathrm{mV}$ (bottom) in the presence (orange trace) and absence (black trace) of GYKI 53 655. C, Overlay of pharmacologically-isolated NMDAR currents (same traces as in $\boldsymbol{A}$ and $\boldsymbol{B}$ ) following a single stimulus (blue trace) or during a $100 \mathrm{~Hz} 6$ stimulus train (orange trace, HFS) at $+40 \mathrm{mV}$ and $-60 \mathrm{mV}$ membrane potential. Stimulation artifacts have been removed for clarity. D, Bar graph of the peak amplitude (left; $t_{(9)}=3.43, p=0.007$, paired $t$ test) or charge transfer (right; $t_{(9)}=3.32, p=0.009$, paired $t$ test) of NMDAR responses following a single stimulus or during a HFS train. $E$, Representative current-clamp recordings from a MLI with a biphasic response in the presence of the NMDAR antagonist D-APV before and after HFS treatment (cell 150203r2). $\boldsymbol{F}$, Time course plot of the eEPSP amplitude before and after HFS in the presence ( $n=4$; open circle) and absence $(n=10$; filled circles) of D-APV. Arrows indicate when the HFS protocol was performed. G, Summary plot of the eEPSP amplitude at $25 \mathrm{~min}$ following HFS expressed as a percentage of the baseline. Error bars indicate SEM. Control data represents the biphasic response from Figure 1 and is shown for comparison purposes. ${ }^{* *} p<0.01,{ }^{* * *} p<0.001$. ns, not significant.

$n=5, \chi_{(5)}^{2}=9.45, p=0.06$, Friedman test) and prevented the slowing in decay kinetics (control $\tau, 15.3 \pm 1.1 \mathrm{~ms},+40 \mathrm{mV} \mathrm{HFS}$ $\tau: 20.1 \pm 1.9 \mathrm{~ms},+$ BAPTA $\tau: 14.1 \pm 1.7 \mathrm{~ms}$ ) observed when HFS was paired with a depolarization step to $+40 \mathrm{mV}$ (Fig. $2 A-D)$.

\section{Activation of NMDARs strengthens postsynaptic inhibitory synapses}

Previous work has shown that fast glutamatergic signaling in MLIs is primarily mediated by synaptic AMPARs, with a smaller contribution from extrasynaptic NMDARs (Clark and Cull-
Candy, 2002). To determine the impact of each receptor subtype following a single stimulus or HFS, we compared the effect of AMPAR and NMDAR selective antagonists on the glutamatergic response (Fig. $3 A-D$ ). Given the strong voltage-dependent block of NMDARs by external $\mathrm{Mg}^{2+}$ at negative membrane potentials, we recorded membrane currents at both -60 and $+40 \mathrm{mV}$. As previously reported (Clark and Cull-Candy, 2002), most of the glutamatergic response from a single stimulation at a holding potential of $-60 \mathrm{mV}$ was blocked by the selective AMPAR antagonist, GYKI $53655(10 \mu \mathrm{M})$ demonstrating the predominant 
A

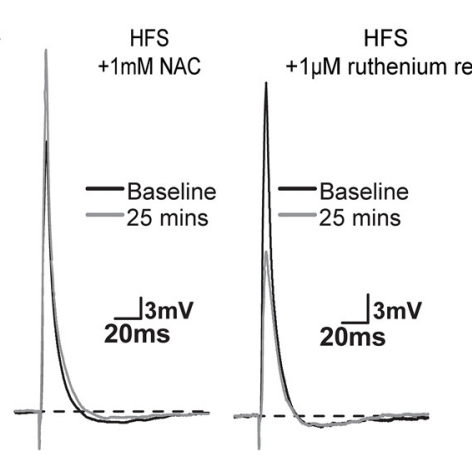

C

no HFS $+10 \mu \mathrm{M}$ cGMP

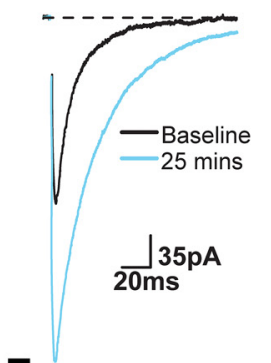

E

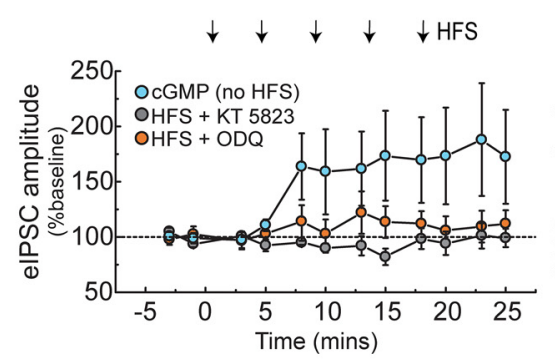

CGMP $+100 \mu \mathrm{M}$ Apocynin

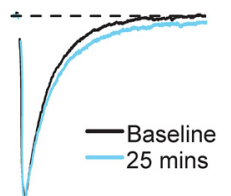

$\frac{\mathrm{J}}{20 \mathrm{~ms}} \mathrm{pA}$
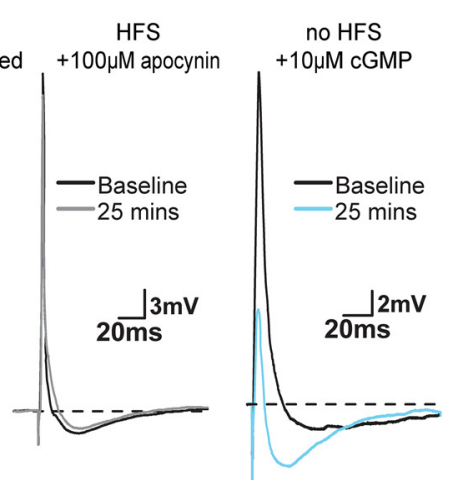

B

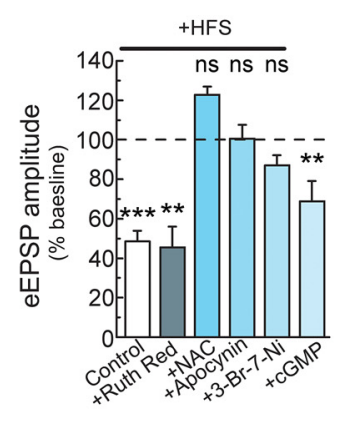

F

D HFS $+5 \mu \mathrm{M}$ KT -5823

HFS
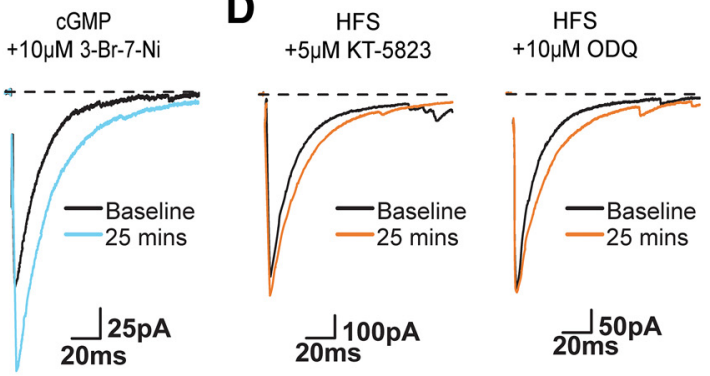

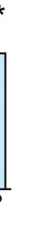
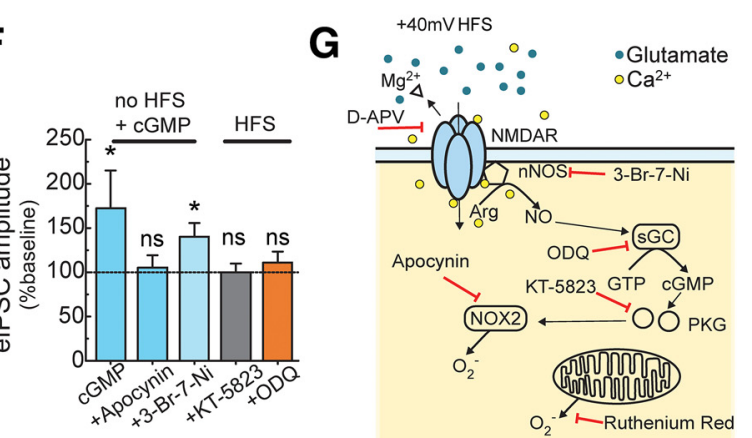

Figure 4. Inhibition of NO synthase and NADPH oxidase blocks iLTP. A, Representative recordings from four different MLIs in current-clamp showing the response to patch electrode perfusion with different pharmacological agents. The first three traces (left to right, cell numbers: 151105r2, 150423r1, 150302r1) show the overlay of responses before (black) and after (gray) HFS. In each case, the recording electrode solution contained either NAC (cell 151105r2), RR (cell 150423r1), or Apo (cell 150302r1). The rightmost trace shows the overlay of two averaged EPSPs at the beginning (black) of patch perfusion with CGMP and after $25 \mathrm{~min}$ (blue; cell 190530r2). B, Summary bar graph of the eEPSP amplitude at 25 min under different conditions expressed as a percentage of the baseline. Error bars indicate SEM. C, Representative $G A B A_{A} R$ membrane currents from three different voltage-clamped MLls at the start (black) and after 25 min (blue) of internal patch perfusion with cGMP (cell numbers left to right: 190122r1, 190311r2, 190530r2). D, Representative GABA $A_{A}$ currents from two different voltage-clamped MLls at baseline (black) and 25 min after HFS (orange) with internal patch perfusion of KT-5823 (PKG inhibitor, cell 191214r2) or ODQ (guanylate cyclase inhibitor, cell 191217r2). $\boldsymbol{E}$, Summary plot of the time course of elPSC amplitude during internal perfusion of CGMP or HFS treatment. $\boldsymbol{F}$, Summary bar graph of the change in elPSC amplitude after 25 min perfusion with internal perfusion of CGMP or HFS treatment with pharmacological blockers. Data are expressed as a percentage of the baseline. $\mathbf{G}$, Schematic diagram outlining the key signaling steps triggered by $\mathrm{Ca}^{2+}{ }_{\text {influx }}$ through NMDARs. An elevation in cytosolic $\mathrm{Ca}^{2+}$, activates nNOS which generates NO from arginine (Arg). NO's action on guanylate cyclase (sGC) generates (GMP from GTP which, in turn, signals to PKG and NOX2 to generate the ROS, superoxide $\left(0_{2}^{-}\right)$. Line markers in red denote the pharmacological target of 3-Br-7-Ni (nNOS), Apo (NOX2), RR (mitochondria), D-APV (NMDAR), KT-5823 (PKG), and ODQ (sGC). Error bars indicate SEM. ${ }^{*} p<0.05,{ }^{* *} p<0.01,{ }^{* * *} p<0.001$. ns, not significant.

contribution of postsynaptic AMPARs (Fig. $3 A, D$ ). In contrast, the glutamatergic response after HFS stimulation at $+40 \mathrm{mV}$, exhibited a greater APV-sensitive component due to a greater contribution of NMDARs (Fig. $3 B-D$ ). In keeping with this, the charge transfer $(Q)$ observed in control conditions at $+40 \mathrm{mV}$ $(\mathrm{Q}=49.1 \pm 8.6 \mathrm{pC}, n=10)$ was similar to the charge transfer measured following bath application of $10 \mu \mathrm{M}$ GYKI 53655 to isolate the NMDAR response $\left(Q=41.7 \pm 12.3 \mathrm{pC}, n=10, W_{(9)}=\right.$ $12, p=0.25$, Wilcoxon signed rank test; Fig. $3 B-D)$. To directly test the hypothesis that NMDAR activation is required for strengthening GABAergic signaling, we repeated the HFS protocol in slices pre-incubated with $10 \mu \mathrm{M}$ D-APV to block NMDARs (Fig. 3E-G). Under these conditions, the reduction in peak eEPSP of the biphasic response failed to occur (Peak 25 :
$111.2 \pm 8 \%, n=4, F_{(5,15)}=0.33, p=0.88$, repeated-measures ANOVA; Fig. $3 E-G)$ establishing that extrasynaptic NMDARs couple signaling between glutamatergic and GABAergic synapses in cerebellar MLIs. In agreement with our previous result in voltage-clamp (Fig. 2), inclusion of high concentrations of BAPTA in the patch electrode also eliminated the reduction in the eEPSP amplitude (Fig. 3G) demonstrating that NMDARs strengthen GABAergic transmission through an elevation in cytosolic $\mathrm{Ca}^{2+}$.

\section{NMDA receptors strengthen GABAergic synapses via a} NO-dependent pathway

Since NMDARs can elevate ROS levels in other neurons (Dugan et al., 1995; Reynolds and Hastings, 1995) and strengthen GABAergic signaling in cerebellar MLIs (Accardi et al., 2014), 


\section{A HFS $+5 \mu \mathrm{M} \mathrm{KN}-93$

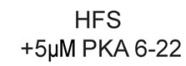 \\ HFS
$+5 \mu \mathrm{M}$ Gö 6983 \\ No HFS +100 nM PMA \\ B}
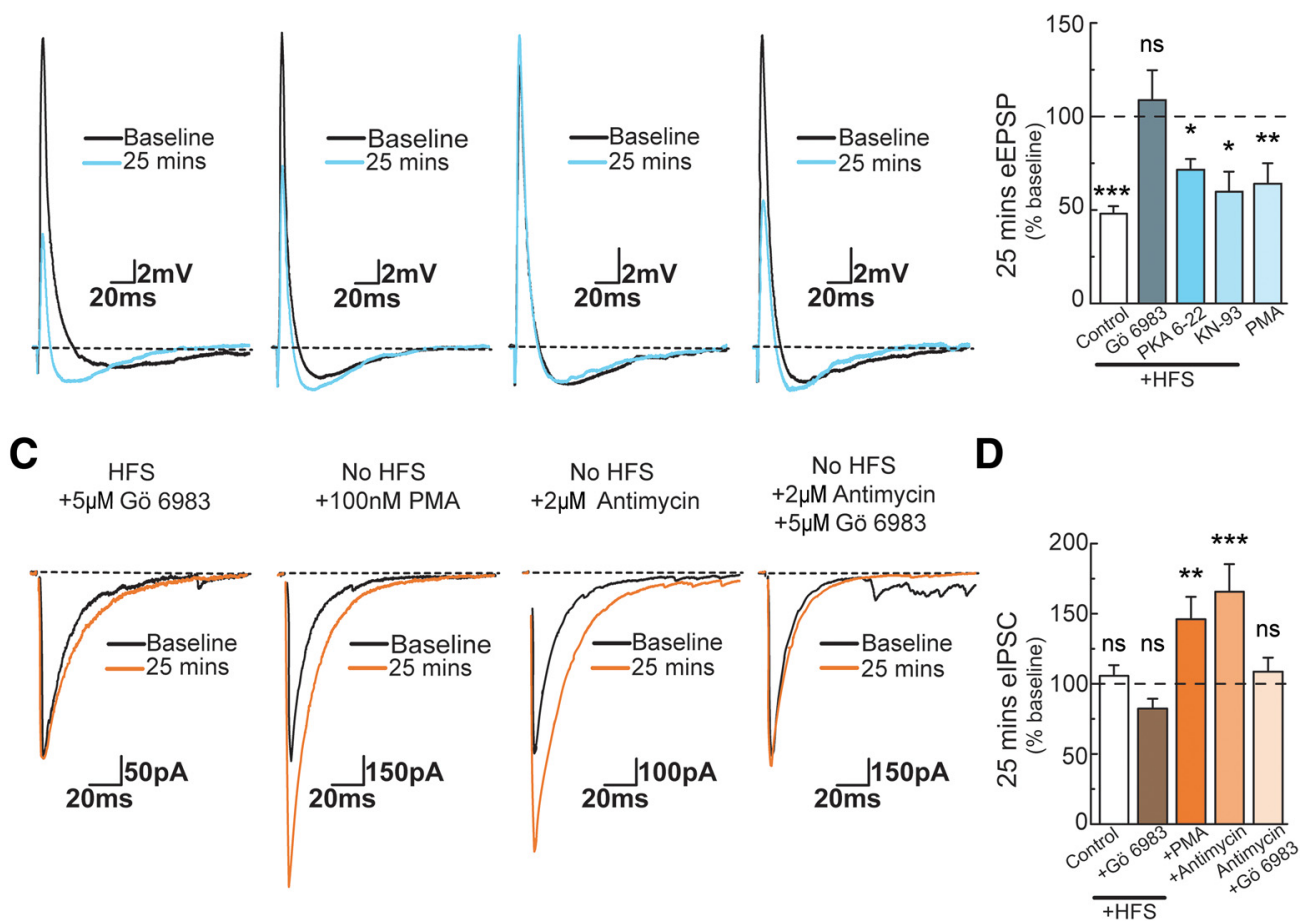

Figure 5. Activation of protein kinase ( strengthens GABAergic synapses. A, Representative recordings from four different MLIs in current-clamp showing the response to patch electrode perfusion with different kinase inhibitors or activators. The first three traces (left to right) show the overlay of responses before (black) and after (blue) HFS. In each case, the recording electrode solution contained either KN-93 (cell 150904r1), PKA 6-22 (cell 150717r2) or Gö 6983 (cell 150629r2). The rightmost trace shows the overlay of two averaged EPSPs at the beginning (black) of patch perfusion with the phorbol ester, PMA, and after 25 min (blue; cell 160204r2). B, Summary bar graph of the eEPSP amplitude at 25 min under different conditions expressed as a percentage of the baseline. Error bars show SEM. C, Representative $G_{A B A} R$ membrane currents from four different MLIs in the voltage-clamp configuration. Synaptically-evoked membrane currents observed before the onset of HFS (black) and after 25 min (orange) in the presence of the PKC inhibitor, Gö 6983 (left; cell 171027r1). The remaining traces correspond to elPSCs observed at the start (black) and after 25 min (orange) of patch perfusion with PMA (cell 160825r1), antimycin A (cell 190630r1), and antimycin A + Gö 6983 (cell 190704r1). D, Summary bar graph of the data shown in $C$ expressed as a percentage of the baseline. Error bars indicate SEM. ${ }^{*} p<0.05,{ }^{* *} p<0.01,{ }^{* *} p<0.001$. ns, not significant.

we tested whether a ROS-dependent mechanism could be responsible for the induction of iLTP in this study. To do this, we first included the antioxidant, $\mathrm{N}$-acetylcysteine (NAC, $1 \mathrm{~mm}$ ), in the patch electrode solution (Fig. $4 \mathrm{~A}$ ) which, as anticipated, eliminated the decline in the net depolarization following HFS $\left(\right.$ Peak $_{25}: 117 \pm 21 \%, n=4, F_{(5,15)}=0.35, p=0.87$, repeated-measures ANOVA; Fig. 4B). Because intracellular NAC does not antagonize $\mathrm{GABA}_{\mathrm{A}} \mathrm{R}$ responses (Accardi et al., 2014, 2015), we concluded that the failure of the HFS protocol to reduce the net depolarization was due to the antioxidant properties of NAC. To determine the origin of ROS production, the pharmacological agents 3-Br-7-Nitroindazole (3-Br-7-Ni; $10 \mu \mathrm{M})$, Apo (100 $\mu \mathrm{M})$, and ruthenium red $(\mathrm{RR} ; 1 \mu \mathrm{M})$ were included in the patch electrode solution to selectively inhibit the activity of neuronal NOS (nNOS or NOS-1), NADPH oxidase (NOX2), and the mitochondrial $\mathrm{Ca}^{2+}$ uniporter, respectively. Although 3-Br-7$\mathrm{Ni}$ also inhibits the other NOS isoforms, iNOS (or NOS-2), and eNOS (NOS-3), RNAseq and data from nNOS-specific $\mathrm{KO}$ animals reveal that only nNOS is expressed in cerebellar MLIs (Huang et al., 1993; Zeisel et al., 2018). The decline in the net depolarization was greatly attenuated by pharmacological block of nNOS and NOX2 with peak responses at $25 \mathrm{~min}$ of $87.1 \pm 5 \%\left(3-\mathrm{Br}-7-\mathrm{Ni}: n=5, F_{(5,20)}=2.40, p=0.073\right.$, repeatedmeasures ANOVA) and $100.6 \pm 7 \%$ (Apo: $n=5, \chi_{(5)}^{2}=6.371$, $p=0.272$, Friedman test), respectively (Fig. $4 A, B$ ). In contrast, inhibition of the mitochondrial $\mathrm{Ca}^{2+}$ uniporter with $1 \mu \mathrm{M} \mathrm{RR}$ did not affect the ability of the HFS protocol to attenuate the eEPSP amplitude (Peak ${ }_{25}: 45.5 \pm 10 \%, n=4, \chi_{(5)}^{2}=17.857, p=0.003$, Friedman test; Fig. $4 A, B$ ). These results demonstrate that nNOS and NOX2 are responsible for the iLTP observed following NMDAR activation.

The fact that iLTP can be eliminated by pharmacological block of nNOS or NOX2 suggests both enzymes share a common signaling pathway. Because prior work has shown that nNOS activity is upstream of NOX2 in neurons (Girouard et al., 2009), we reasoned that a similar sequence of events may occur in MLIs. For example, a rise in NO levels through nNOS activity is known to first elevate cGMP levels via guanylate cyclase which in turn activates PKG with downstream activation of NOX2 (Girouard et al., 2009). To determine whether a similar sequence of events occurs in MLIs, we directly stimulated PKG by perfusing a non-hydrolyzable cGMP analog through our patch pipette (Fig. $4 A-C, E, F)$. In separate current- and voltage-clamp experiments, direct activation of PKG resulted in a decrease in eEPSP amplitude $\left(\right.$ Peak $_{25}: 68.7 \pm 10 \%, n=7, F_{(6,30)}=4.56, p=0.003$, repeated-measures ANOVA) and a potentiation of the eIPSC amplitude $\left(\right.$ Peak $_{25}: 180.3 \pm 10 \%, n=6, F_{(5,25)}=3.09, p=0.02$, repeated-measures ANOVA), respectively (Fig. $4 A, C$ ) demonstrating that iLTP is regulated by cGMP. Consistent with our HFS treatment, intracellular perfusion of cGMP also resulted in a slowing of decay kinetics (cGMP $\tau: 21.8 \pm 3.7 \mathrm{~ms}$ ). Furthermore, pharmacological block of nNOS with 3-Br-7-Ni failed to eliminate the eIPSC potentiation $\left(\right.$ Peak $_{25}: 139.9 \pm 15 \%, n=6, F_{(5,25)}$ $=2.87, p=0.03$, repeated-measures ANOVA) whereas block of 

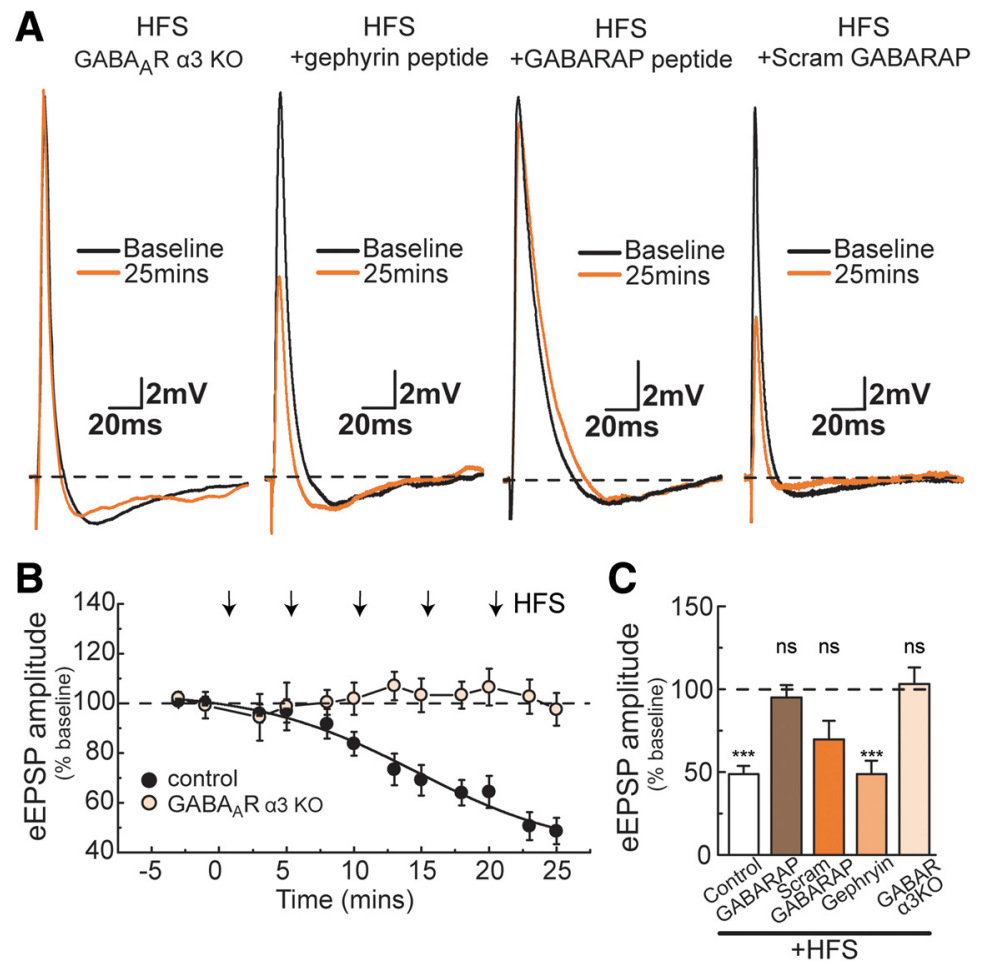

Figure 6. ILTP is dependent on $\alpha 3$-containing GABA $A_{A}$ receptors and GABARAP. $A$, Overlay of eEPSP recordings from four different MLIs in current-clamp configuration before the start of HFS (black) and after 25 min (orange). Left to right, Representative examples of recordings from MLIs from a GABA $R \alpha 3 \mathrm{KO}$ mouse (cell 151110r1) and wild-type cells perfused with the gephyrin interfering peptide (cell 150612r1), GABARAP interfering peptide (cell 150518r1) and scrambled GABARAP peptide (cell 150908r1). $\boldsymbol{B}$, Time course of the averaged eEPSP amplitude before and after HFS for the biphasic response from Figure 1 and in recordings from $\mathrm{GABA}_{A} \mathrm{R} \alpha 3 \mathrm{KO}$ mice. C, Summary bar graph of eEPSP amplitude at $25 \mathrm{~min}$ following HFS expressed as a percentage of the baseline. Error bars indicate SEM. ${ }^{* * *} p<0.001$. ns, not significant.

NOX2 activity with Apo eliminated the effect of the cGMP analog $\left(\right.$ Peak $_{25}: \quad 105 \pm 14 \%, \quad n=6, \quad \chi_{(5)}^{2}=5.33, \quad p=0.37$, Friedman test; Fig. 4C,F). Conversely, including the PKG antagonist, KT-5823 $(5 \mu \mathrm{M})$, in our internal patch solution eliminated any potentiation of the eIPSC amplitude following HFS $\left(\right.$ Peak $_{25}$ : 99.3 $\pm 8 \%, n=7, F_{(6,30)}=0.92, p=0.48$, repeated-measures ANOVA; Fig. $4 D-F)$. Finally, pharmacological block of guanylate cyclase by internal perfusion of ODQ $(10 \mu \mathrm{M})$ also prevented any potentiation of the eIPSC following HFS (Peak ${ }_{25}$ : $112 \pm 12 \%, n=7, F_{(6,30)}=0.78, p=0.57$, repeated-measures ANOVA; Fig. $4 D-F)$. Together, these data demonstrate that nNOS activation is upstream of NOX2 in a PKG-dependent pathway as summarized in Figure $4 G$.

\section{PKC strengthens GABAergic synapses following NMDA receptor activation}

Several kinases have been shown to regulate the strength of GABAergic synapses by triggering the recruitment of synaptic $\mathrm{GABA}_{\mathrm{A}}$ Rs (Luscher et al., 2011). Many of these kinases also possess ROS-sensitive amino-acid residues in their regulatory or catalytic domains which can affect kinase activity. Specifically PKA, $\mathrm{PKC}$, and CaMKII can be activated by ROS in addition to their canonical activation pathways (Knock and Ward, 2011). Given this, we reasoned that the iLTP observed in the present study could be because of ROS action on kinase activity.

To test this, we performed the HFS experiment while perfusing individual MLIs with either KN-93 $(5 \mu \mathrm{M})$, protein kinase inhibitor-(6-22)-amide peptide $(5 \mu \mathrm{M})$ or Gö $6983(5 \mu \mathrm{M})$ to selectively inhibit CaMKII, PKA, and PKC, respectively (Fig. 5).
Pharmacological inhibition of PKA and CaMKII still resulted in a decline in the eEPSP amplitude following HFS with peak responses after 25 $\min$ of $71.5 \pm 5 \% \quad\left(n=6, \quad \chi_{(5)}^{2}=\right.$ 23.23, $p=0.0003$, Friedman test) and $57.2 \pm 9 \%$, respectively $\left(n=4, \chi_{(5)}^{2}=\right.$ 11.43, $p=0.04$, Friedman test; Fig. $5 A, B)$. In contrast, inhibition of PKC by $5 \mu \mathrm{M}$ Gö 6983 eliminated the induction of iLTP by the HFS protocol (Fig. 5A) with peak responses at 25 min of $108.7 \pm 16 \%\left(n=5, \chi_{(5)}^{2}=\right.$ $5.43, p=0.36$, Friedman test; Fig. $5 B$ ). Similarly, inclusion of $5 \mu \mathrm{M}$ Gö 6983 in voltage-clamp experiments also prevented iLTP (Fig. 5C,D). In support of this, direct activation of PKC with PMA (100 nM), elicited a similar time-dependent onset of iLTP in both current- and voltageclamp experiments (Fig. 5A-D). We observed a decrease in the eEPSP to $63.9 \pm 12 \%$ of the baseline eEPSP $\left(n=4, \chi_{(4)}^{2}=13.8, p=0.008\right.$, Friedman test) in current-clamp recordings and an increase to 146 $\pm 16 \%$ of the baseline eIPSC $(n=6$, repeated-measures ANOVA, $F_{(4,20)}$ $=4.77, p=0.007)$ in voltage-clamp (Fig. 5A-D). Interestingly, we also observed iLTP following the inclusion of the metabolic uncoupler, antimycin $\mathrm{A}$, to generate mitochondrial ROS in MLIs which was eliminated by the PKC inhibitor (Fig. 5C,D). This latter finding demonstrates that our previous study linking mitochondrial ROS (mROS) to the strengthening of GABAergic signaling in cerebellar MLIs is mediated through PKC (Accardi et al., 2014). A similar PKC-dependent pathway may also explain the effect of mROS on $\alpha 6$-containing $\mathrm{GABA}_{\mathrm{A}} \mathrm{Rs}$ of cerebellar granule cells (Accardi et al., 2015). Together, these data show that ROS-induced iLTP in MLIs relies on a PKC-dependent signaling pathway.

\section{Synapse strengthening requires GABARAP and recruitment of $\alpha 3$-containing $\mathrm{GABA}_{\mathrm{A}}$ receptors}

Although MLIs express both $\alpha 1$ - and $\alpha 3$-containing $\mathrm{GABA}_{\mathrm{A}}$ receptors (Laurie et al., 1992), previous work from our laboratory has shown that ROS-mediated synapse strengthening relies exclusively on the recruitment of postsynaptic $\alpha 3$-containing receptors (Accardi et al., 2014). Though more numerous, $\alpha 1$ containing $\mathrm{GABA}_{\mathrm{A}} \mathrm{R}$ synapses are unaffected by ROS in both stellate and granule cells of the cerebellum (Accardi et al., 2014, 2015). To determine whether NMDAR-dependent strengthening of GABAergic transmission also relies on $\alpha 3$-containing receptors, we repeated the HFS protocol in cerebellar slices from $\alpha 3$ KO mice (Fig. 6). As anticipated, GABAergic strengthening elicited by HFS was absent in MLIs lacking the $\alpha 3$-subunit $\left(\right.$ Peak $_{25}$ : $115.3 \pm 15 \%, n=7, \quad \chi_{(5)}^{2}=6.59, p=0.25$, Friedman test; Fig. $6 A-C)$ confirming that the strengthening of MLI inhibitory synapses is subunit-dependent.

$\mathrm{GABA}_{\mathrm{A}} \mathrm{Rs}$ interact with a number of scaffolding proteins which regulate receptor trafficking and clustering at inhibitory 
synapses. To investigate which protein interactions are responsible for synaptic targeting of $\alpha 3$-containing $\mathrm{GABA}_{\mathrm{A}} \mathrm{Rs}$, we focused on two prominent $\mathrm{GABA}_{\mathrm{A}} \mathrm{R}$ scaffolding proteins linked to inhibitory synapse plasticity (Petrini and Barberis, 2014): gephyrin (Tyagarajan and Fritschy, 2014) and GABARAP (Wang et al., 1999). Previous work has identified that gephyrin binds directly to the GABA $\alpha 3$-subunit (Tretter et al., 2011) while GABARAP is known to bind to the $\gamma 2$-subunit (Wang et al., 1999). In keeping with this, coexpression of recombinant $\alpha 3 \beta 2 \gamma 2 \mathrm{GABA}_{\mathrm{A}}$ receptors in HEK293 cells with either gephyrin or GABARAP revealed that both scaffolding proteins coimmunoprecipitate with the ion-channel complex (Fig. 7). Consequently, we used two short-chain peptides, namely $\alpha 3$ derived peptide (Tretter et al., 2011; Maric et al., 2014) and K1 GABARAP peptide (Weiergräber et al., 2008), to interfere with the binding of gephyrin or GABARAP, respectively, to recombinantly expressed $\alpha 3$-containing $\mathrm{GABA}_{\mathrm{A}}$ Rs (see Materials and Methods; Fig. 7B). These peptides were then used in separate electrophysiology experiments to test for the role of gephyrin and/or GABARAP in MLI inhibitory synapse strengthening.

Each peptide was included in the patch electrode solution during HFS protocols to interfere with the binding of the target protein (Fig. $6 A, C$ ). In all cases, we waited 15 min from breakthrough before beginning the HFS protocol to allow the peptide to dialyze throughout the neuron and prevent protein-protein interactions. We observed that the rate and degree of onset of synapse strengthening induced by HFS was unaffected by the $\alpha 3$-derived, gephyrin-inhibiting peptide $\left(\right.$ Peak $_{25}: 48.7 \pm 8 \%, n=5, F_{(4,20)}=6.86, p=0.0007$, repeatedmeasures ANOVA; Fig. $6 A, C$ suggesting that $\alpha 3$-containing $\mathrm{GABA}_{\mathrm{A}} \mathrm{Rs}$ are not recruited to inhibitory synapses via a gephyrin-dependent mechanism. In contrast, inclusion of the K1 GABARAP peptide in the patch electrode solution eliminated the induction of synapse strengthening (Fig. $6 A, C ; F_{(5,40)}=1.22$, $p=0.35$, repeated-measures ANOVA) indicating that GABARAP is required for the synaptic recruitment of $\alpha 3$-containing $\mathrm{GABA}_{\mathrm{A}} \mathrm{Rs}$. In agreement with this, pre-incubation of the K1 GABARAP peptide with lysates of cells coexpressing $\alpha 3$-containing $\mathrm{GABA}_{\mathrm{A}}$ Rs disrupted GABARAP binding establishing the specificity of the interaction (Fig. $7 C, D$ ). Moreover, a scrambled version of the K1 GABARAP peptide failed to disrupt the binding of GABARAP to the GABAR complex (Fig. $7 C, D$ ). Additionally, the scrambled peptide failed to prevent the induction of iLTP by the HFS protocol $(n=4,69.6 \pm 11 \%$; Fig. $6 A, C)$ further confirming the specificity of the K1 GABARAP peptide interaction with $\alpha 3$-containing $\mathrm{GABA}_{\mathrm{A}} \mathrm{Rs}$.

\section{Discussion}

The present study advances our understanding of how NO signaling regulates the excitatory/inhibitory balance in the mammalian brain in several new and important ways. First, we show that NO generated by NMDAR activation strengthens inhibitory GABAergic synapses through a series of sequential steps involving nNOS, NADPH oxidase, and PKC as outlined in Figure 8 These observations are distinct from previous work, which has shown that NMDARs strengthen $\mathrm{GABA}_{\mathrm{A}}$ receptor synapses through a different pathway involving CaMKII. Second, we show that the strengthening of $\alpha 3$-containing $\mathrm{GABA}_{\mathrm{A}} \mathrm{R}$ synapses in MLIs is reliant on the scaffolding protein, GABARAP, rather than gephyrin. Our data does not exclude a role for gephyrin 


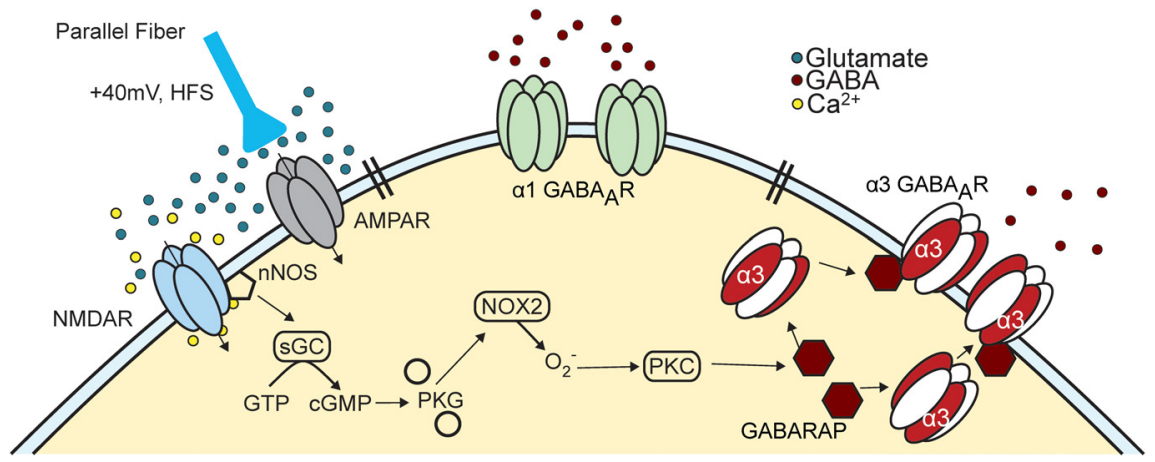

Figure 8. Summary of iLTP signaling pathway. Schematic summarizing the main signaling events and molecules that lead to the selective recruitment of $\alpha 3$-containing $\mathrm{GABA}_{A} \mathrm{Rs}$ into inhibitory synapses of cerebellar MLIs. HFS of parallel fibers from granule cells stimulates extrasynaptic NMDARs of MLIs and activates nNOS through the influx of external $\mathrm{Ca}^{2+}$. nNOS generates N0, which acts on guanylate cyclase (sGC) elevating CGMP which, in turn, stimulates PKG and NOX2. We speculate the production of superoxide by NOX2 leads to the activation of PKC and the recruitment of GABA Rs via a GABARAP-dependent pathway. This signaling pathway selectively acts on $\alpha 3$-containing $\mathrm{GABA}_{\mathrm{A}} \mathrm{Rs}$ and does not affect synapses containing $\alpha 1-\mathrm{GABA}_{A} \mathrm{Rs}$.

at $\alpha 3$-receptor synapses but nevertheless highlights that GABARAP has a prominent role in the recruitment process. Finally, given the widespread but cell-selective expression of the NMDAR/nNOS complex, our findings suggest that NO control of GABAergic synapses through NMDARs may be more widespread in the vertebrate brain than has been appreciated.

\section{NO strengthens inhibitory GABAergic synapses following NMDAR activation}

Multiple presynaptic and postsynaptic mechanisms elicit longterm changes in the efficacy of GABAergic synapses (Kullmann et al., 2012) with one of the most prominent pathways involving an increase in the number of $\mathrm{GABA}_{\mathrm{A}}$ receptors per synapse (Luscher et al., 2011). NMDAR-mediated strengthening of GABAergic synapses has been linked to an increase in cytoplasmic $\mathrm{Ca}^{2+}$ and subsequent activation of CaMKII (Marsden et al., 2007; Luscher et al., 2011; Chiu et al., 2019). Although $\mathrm{Ca}^{2+}$ entry through NMDARs is still a requirement in inhibitory synapse strengthening of MLIs, we excluded a role for CaMKII because its specific kinase inhibitor, KN-93, did not affect synaptic plasticity (compare Fig. 5).

A recent study has shown that postsynaptic NMDARs of granule cells can enhance inhibitory transmission by the retrograde action of $\mathrm{NO}$ on presynaptic GABA terminals of Golgi cells in the rat cerebellum (Mapelli et al., 2016). Although we cannot completely exclude a presynaptic role of NO in the present study on the mouse cerebellum, our data suggest that almost all the molecular events triggered by NMDARs in MLIs are predominantly postsynaptic. For example, it is unlikely that a presynaptic mechanism could explain the effect of internal patch perfusion of the GABARAP blocking peptide on inhibitory synapse strengthening (Figs. 6, 7) given that the peptide is membrane impermeant and thus confined to the cytoplasm of the recorded cell. Likewise, the effect of internal patch perfusion with cGMP and its inhibition by Apo (Fig. 4) suggests that the signaling pathway involving both cGMP and NOX2 is postsynaptic. Furthermore, if NO was acting through a purely presynaptic mechanism, enhanced release of presynaptic GABA by NO would be expected to be observed at all inhibitory synapses. However, our data demonstrate that the enhancement of GABAergic transmission by NMDARs and NO occurs only at $\alpha 3$-containing inhibitory synapses and not $\alpha 1$-receptor synapses (Fig. 6). It is possible that NO has both presynaptic and postsynaptic targets at inhibitory synapses of MLIs. In this case, NO would selectively enhance presynaptic GABA release from $\alpha 3$ - and not $\alpha 1$-receptor synapses while triggering the postsynaptic cell to generate NO, cGMP, activate $\mathrm{NOX} 2$ and $\mathrm{PKC}$, and finally promote the recruitment of postsynaptic $\alpha 3$-receptors.

Interestingly, a similar dual effect of NO might be at play at the inhibitory Golgi cell-granule cell synapse. In agreement with this, we have previously shown that reactive oxygen species enhance recruitment of postsynaptic $\alpha 6$ - but not $\alpha 1$-containing $\mathrm{GABA}_{\mathrm{A}} \mathrm{Rs}$ in mouse granule cells (Accardi et al., 2015), whereas others have shown a presynaptic action of NO on GABA release from rat Golgi cells (Mapelli et al., 2016). Differential regulation of input-specific GABAergic synapses onto the same neuron has recently been described in the cerebral cortex (Chiu et al., 2018) and striatum (Paraskevopoulou et al., 2019), consequently, it is possible that a similar arrangement is found in both inhibitory synapses of MLIs and granule cells of the cerebellum. An important caveat to both presynaptic and postsynaptic roles of NO in granule cells, however, is that nNOS expression in the presynaptic terminals of Golgi cells is high in the rat but almost completely absent from the mouse, particularly mice with the C57BL/6 background used in this study (Kaplan et al., 2013). Accordingly, NO may act primarily on presynaptic Golgi cell terminals in the rat and through a postsynaptic pathway in granule cells of the mouse. Whether nNOS expression at MLI inhibitory synapses is similarly species-dependent has yet to be examined.

\section{GABAergic synapse strengthening is dependent on the scaffolding protein, GABARAP}

Our experiments establish a key role for GABARAP in the strengthening of GABAergic synapses. Although different mechanisms may anchor $\mathrm{GABA}_{\mathrm{A}} \mathrm{Rs}$ at central synapses, the prevalent view is that gephyrin plays a prominent role in binding the $\alpha 1-3$ (Tretter et al., 2008; Mukherjee et al., 2011; Tretter et al., 2011) and/or $\beta 2-3$ (Kowalczyk et al., 2013) $\mathrm{GABA}_{\mathrm{A}} \mathrm{R}$ subunits to the cytoskeleton (Tyagarajan and Fritschy, 2014). Although gephyrin-independent clustering of postsynaptic $\mathrm{GABA}_{\mathrm{A}} \mathrm{Rs}$ has been reported (Kneussel et al., 2001; Levi et al., 2004; Panzanelli et al., 2011) the role of other accessory proteins, such as GABARAP (Wang et al., 1999) and/or the dystrophin-glycoprotein complex (Pribiag et al., 2014), has received less attention. Our data argue in favor of GABARAP playing an important role in the recruitment of $\alpha 3$-containing $\mathrm{GABA}_{\mathrm{A}} \mathrm{Rs}$ during synapse strengthening (compare Fig. 6). Although, we cannot exclude a role for gephyrin at $\alpha 3$-receptor synapses, costaining for the $\alpha 3$ subunit and gephyrin show very little overlap (Accardi et al., 2014) suggesting that $\alpha 3$ $\mathrm{GABA}_{\mathrm{A}} \mathrm{R}$ subunits may associate with another trafficking/scaffolding protein in MLIs. Our findings are consistent with studies on cultured hippocampal neurons showing that there are low GABARAP levels at inhibitory synapses under basal conditions (Kittler et al., 2001) and that the levels increase following 
chemically-induced strengthening of inhibitory synapses (Marsden et al., 2007).

\section{Widespread and cell-selective expression of NNOS $^{+}$neurons in the mammalian brain}

nNOS $^{+}$neurons are expressed throughout the CNS (Vincent and Kimura, 1992; Southam and Garthwaite, 1993; Rodrigo et al., 1994) and are involved in many different CNS functions that include learning and memory, sleep, feeding behaviors, movement, pain, anxiety, and reproductive activity (Garthwaite, 2008; Steinert et al., 2010; Chachlaki et al., 2017; Garthwaite, 2019). It has long been recognized that nNOS activation and the downstream production of cGMP is linked to glutamatergic signaling, primarily through NMDARs in the cerebellum (Southam et al., 1991). Of note, nNOS activity is highest in the cerebellum compared with other brain regions (Förstermann et al., 1990) because of several nNOS ${ }^{+}$neuronal types, including granule cells and MLIs, but is curiously absent from Purkinje cells, the sole output neuron of the cerebellar cortex (Vincent and Kimura, 1992; Rodrigo et al., 1994). Our data establish a new function for nNOS in MLIs, which is part of a sequential signaling pathway that strengthens inhibitory GABAergic synapses following NMDAR activation. NMDARs of MLIs are also involved in the tight coupling between neuronal communication and local blood flow during functional hyperemia where activation of NMDARs generates NO, which promotes vasodilation of local capillaries (Rancillac et al., 2006).

Together, these observations suggest that NMDARs expressed by MLIs fulfill multiple functions that control the excitability of MLIs while impacting the physiological state of the surrounding cells and tissue. In keeping with this, unpublished data from our laboratory reveals that NMDARs also directly modulate MLI excitability (RPD Alexander and D. Bowie, unpublished observation) through a signaling pathway that leads to a hyperpolarizing shift in sodium channel (Nav) activation and inactivation recently described (Alexander et al., 2019). Interestingly, this pathway does not involve PKC but instead signals through the actions of CaMKII (Alexander and Bowie, unpublished observation) suggesting that $\mathrm{Ca}^{2+}$ influx through NMDARs in MLIs triggers a bifurcating pathway involving both CaMKII and nNOS. Given the multiple actions of NMDARs and nNOS in MLIs, it is tempting to speculate that similar roles are found in other nNOS ${ }^{+}$cells of the CNS. On that note, NMDAR activation and the generation of ROS or NO also lead to the strengthening of GABAergic transmission in cerebellar granule cells (Accardi et al., 2015; Mapelli et al., 2016) and vasodilation of local blood vessels (Mapelli et al., 2017) in a manner reminiscent of MLIs. Given this, it would be interesting in future studies to examine whether NMDAR activation of other nNOS ${ }^{+}$neurons outside the cerebellum similarly regulate GABAR plasticity and local blood flow.

\section{References}

Accardi MV, Brown P, Miraucourt LS, Orser BA, Bowie D (2015) $\alpha 6$ Containing GABAA receptors are the principal mediators of inhibitory synapse strengthening by insulin in cerebellar granule cells. J Neurosci 35:9676-9688

Accardi MV, Daniels BA, Brown P, Fritschy JM, Tyagarajan SK, Bowie D (2014) Mitochondrial reactive oxygen species regulate the strength of inhibitory GABA-mediated synaptic transmission. Nat Commun 5: 3168.

Alexander RPD, Mitry J, Sareen V, Khadra A, Bowie D (2019) Cerebellar stellate cell excitability is coordinated by shifts in the gating behavior of voltage-gated $\mathrm{Na}(+)$ and A-type $\mathrm{K}(+)$ channels. eNeuro 6:ENEURO. 0126-19.2019.

Arenz A, Silver RA, Schaefer AT, Margrie TW (2008) The contribution of single synapses to sensory representation in vivo. Science 321:977-980.

Bayer KU, LeBel E, McDonald GL, O’Leary H, Schulman H, De Koninck P (2006) Transition from reversible to persistent binding of CaMKII to postsynaptic sites and NR2B. J Neurosci 26:1164-1174.

Bello O, Blair K, Chapleau C, Larimore JL (2013) Is memantine a potential therapeutic for Rett syndrome? Front Neurosci 7:245.

Bredt DS (1999) Endogenous nitric oxide synthesis: biological functions and pathophysiology. Free Radic Res 31:577-596.

Brenman JE, Christopherson KS, Craven SE, McGee AW, Bredt DS (1996a) Cloning and characterization of postsynaptic density 93, a nitric oxide synthase interacting protein. J Neurosci 16:7407-7415.

Brenman JE, Chao DS, Gee SH, McGee AW, Craven SE, Santillano DR, Wu Z, Huang F, Xia H, Peters MF, Froehner SC, Bredt DS (1996b) Interaction of nitric oxide synthase with the postsynaptic density protein PSD-95 and $\alpha 1$-syntrophin mediated by PDZ domains. Cell 84:757-767.

Brown GC (2010) Nitric oxide and neuronal death. Nitric Oxide 23:153-165.

Chachlaki K, Garthwaite J, Prevot V (2017) The gentle art of saying NO: how nitric oxide gets things done in the hypothalamus. Nat Rev Endocrinol 13:521-535.

Chadderton P, Margrie TW, Hausser M (2004) Integration of quanta in cerebellar granule cells during sensory processing. Nature 428:856-860.

Chiu CQ, Barberis A, Higley MJ (2019) Preserving the balance: diverse forms of long-term GABAergic synaptic plasticity. Nat Rev Neurosci 20:272281.

Chiu CQ, Martenson JS, Yamazaki M, Natsume R, Sakimura K, Tomita S, Tavalin SJ, Higley MJ (2018) Input-specific NMDAR-dependent potentiation of dendritic GABAergic inhibition. Neuron 97:368-377.e3.

Clark BA, Cull-Candy SG (2002) Activity-dependent recruitment of extrasynaptic NMDA receptor activation at an AMPA receptor-only synapse. J Neurosci 22:4428-4436.

Coddington LT, Rudolph S, Vande Lune P, Overstreet-Wadiche L, Wadiche JI (2013) Spillover-mediated feedforward inhibition functionally segregates interneuron activity. Neuron 78:1050-1062.

Dugan LL, Sensi SL, Canzoniero LM, Handran SD, Rothman SM, Lin TS, Goldberg MP, Choi DW (1995) Mitochondrial production of reactive oxygen species in cortical neurons following exposure to N-methyl-D-aspartate. J Neurosci 15:6377-6388.

Förstermann U, Gorsky LD, Pollock JS, Schmidt HH, Heller M, Murad F (1990) Regional distribution of EDRF/NO-synthesizing enzyme(s) in rat brain. Biochem Biophys Res Commun 168:727-732.

Fritschy JM, Panzanelli P (2006) Molecular and synaptic organization of GABAA receptors in the cerebellum: effects of targeted subunit gene deletions. Cerebellum 5:275-285.

Garthwaite J (2008) Concepts of neural nitric oxide-mediated transmission. Eur J Neurosci 27:2783-2802.

Garthwaite J (2016) From synaptically localized to volume transmission by nitric oxide. J Physiol 594:9-18.

Garthwaite J (2019) NO as a multimodal transmitter in the brain: discovery and current status. Br J Pharmacol 176:197-211.

Girouard H, Wang G, Gallo EF, Anrather J, Zhou P, Pickel VM, Iadecola C (2009) NMDA receptor activation increases free radical production through nitric oxide and NOX2. J Neurosci 29:2545-2552.

Glasgow NG, Siegler Retchless B, Johnson JW (2015) Molecular bases of NMDA receptor subtype-dependent properties. J Physiol 593:83-95.

Gnegy ME (2000) $\mathrm{Ca}^{2+} /$ calmodulin signaling in NMDA-induced synaptic plasticity. Crit Rev Neurobiol 14:91-129.

Hardingham GE, Bading H (2003) The Yin and Yang of NMDA receptor signalling. Trends Neurosci 26:81-89.

Hu C, Chen W, Myers SJ, Yuan H, Traynelis SF (2016) Human GRIN2B variants in neurodevelopmental disorders. J Pharmacol Sci 132:115-121.

Huang PL, Dawson TM, Bredt DS, Snyder SH, Fishman MC (1993) Targeted disruption of the neuronal nitric oxide synthase gene. Cell 75:1273-1286.

Jörntell H, Ekerot CF (2006) Properties of somatosensory synaptic integration in cerebellar granule cells in vivo. J Neurosci 26:11786-11797.

Kaplan JS, Mohr C, Rossi DJ (2013) Opposite actions of alcohol on tonic GABA(A) receptor currents mediated by nNOS and PKC activity. Nat Neurosci 16:1783-1793.

Kiss JP, Vizi ES (2001) Nitric oxide: a novel link between synaptic and nonsynaptic transmission. Trends Neurosci 24:211-215. 
Kittler JT, Rostaing P, Schiavo G, Fritschy JM, Olsen R, Triller A, Moss SJ (2001) The subcellular distribution of GABARAP and its ability to interact with NSF suggest a role for this protein in the intracellular transport of GABA(A) receptors. Mol Cell Neurosci 18:13-25.

Kneussel M, Brandstatter JH, Gasnier B, Feng G, Sanes JR, Betz H (2001) Gephyrin-independent clustering of postsynaptic GABA(A) receptor subtypes. Mol Cell Neurosci 17:973-982.

Knock GA, Ward JP (2011) Redox regulation of protein kinases as a modulator of vascular function. Antioxid Redox Signal 15:1531-1547.

Köhr G, Eckardt S, Lüddens H, Monyer H, Seeburg PH (1994) NMDA receptor channels: subunit-specific potentiation by reducing agents. Neuron 12:1031-1040.

Kowalczyk S, Winkelmann A, Smolinsky B, Forstera B, Neundorf I, Schwarz G, Meier JC (2013) Direct binding of GABAA receptor $\beta 2$ and $\beta 3$ subunits to gephyrin. Eur J Neurosci 37:544-554.

Kullmann DM, Moreau AW, Bakiri Y, Nicholson E (2012) Plasticity of inhibition. Neuron 75:951-962.

Laurie DJ, Seeburg PH, Wisden W (1992) The distribution of 13 GABAA receptor subunit mRNAs in the rat brain: II. Olfactory bulb and cerebellum. J Neurosci 12:1063-1076.

Lee DZ, Chung JM, Chung K, Kang M-G (2012) Reactive oxygen species (ROS) modulate AMPA receptor phosphorylation and cell-surface localization in concert with pain-related behavior. PAIN 153:1905-1915.

Levi S, Logan SM, Tovar KR, Craig AM (2004) Gephyrin is critical for glycine receptor clustering but not for the formation of functional GABAergic synapses in hippocampal neurons. J Neurosci 24:207-217.

Li Z, Ji G, Neugebauer V (2011) Mitochondrial reactive oxygen species are activated by mGluR5 through IP3 and activate ERK and PKA to increase excitability of amygdala neurons and pain behavior. J Neurosci 31:11141127.

Liu J, Chang L, Song Y, Li H, Wu Y (2019) The role of NMDA receptors in Alzheimer's disease. Front Neurosci 13:43.

Lu YF, Kandel ER, Hawkins RD (1999) Nitric oxide signaling contributes to late-phase LTP and CREB phosphorylation in the hippocampus. J Neurosci 19:10250-10261.

Luscher B, Fuchs T, Kilpatrick CL (2011) GABAA receptor trafficking-mediated plasticity of inhibitory synapses. Neuron 70:385-409.

Mapelli J, Gandolfi D, Vilella A, Zoli M, Bigiani A (2016) Heterosynaptic GABAergic plasticity bidirectionally driven by the activity of pre- and postsynaptic NMDA receptors. Proc Natl Acad Sci U S A 113:9898-9903.

Mapelli L, Gagliano G, Soda T, Laforenza U, Moccia F, D’Angelo EU (2017) Granular layer neurons control cerebellar neurovascular coupling through an NMDA receptor/NO-dependent system. J Neurosci 37:13401351.

Maric HM, Kasaragod VB, Hausrat TJ, Kneussel M, Tretter V, Stromgaard $\mathrm{K}$, Schindelin H (2014) Molecular basis of the alternative recruitment of GABA(A) versus glycine receptors through gephyrin. Nat Commun 5:5767.

Marsden KC, Beattie JB, Friedenthal J, Carroll RC (2007) NMDA receptor activation potentiates inhibitory transmission through GABA receptorassociated protein-dependent exocytosis of $\mathrm{GABA}(\mathrm{A})$ receptors. J Neurosci 27:14326-14337.

Milnerwood AJ, Raymond LA (2010) Early synaptic pathophysiology in neurodegeneration: insights from Huntington's disease. Trends Neurosci 33:513-523.

Mukherjee J, Kretschmannova K, Gouzer G, Maric HM, Ramsden S, Tretter V, Harvey K, Davies PA, Triller A, Schindelin H, Moss SJ (2011) The residence time of GABA(A)Rs at inhibitory synapses is determined by direct binding of the receptor $\alpha 1$ subunit to gephyrin. J Neurosci 31:1467714687.

Nakahiro M, Arakawa O, Narahashi T, Ukai S, Kato Y, Nishinuma K, Nishimura T (1992) Dimethyl sulfoxide (DMSO) blocks GABA-induced current in rat dorsal root ganglion neurons. Neurosci Lett 138:5-8.

Panzanelli P, Gunn BG, Schlatter MC, Benke D, Tyagarajan SK, Scheiffele P, Belelli D, Lambert JJ, Rudolph U, Fritschy JM (2011) Distinct mechanisms regulate GABAA receptor and gephyrin clustering at perisomatic and axo-axonic synapses on CA1 pyramidal cells. J Physiol 589:49594980.

Paoletti P, Bellone C, Zhou Q (2013) NMDA receptor subunit diversity: impact on receptor properties, synaptic plasticity and disease. Nat Rev Neurosci 14:383-400.
Paraskevopoulou F, Herman MA, Rosenmund C (2019) Glutamatergic Innervation onto Striatal Neurons Potentiates GABAergic Synaptic Output. J Neurosci 39:4448-4460.

Petrini EM, Barberis A (2014) Diffusion dynamics of synaptic molecules during inhibitory postsynaptic plasticity. Front Cell Neurosci 8:300.

Petrini EM, Ravasenga T, Hausrat TJ, Iurilli G, Olcese U, Racine V, Sibarita JB, Jacob TC, Moss SJ, Benfenati F, Medini P, Kneussel M, Barberis A (2014) Synaptic recruitment of gephyrin regulates surface GABAA receptor dynamics for the expression of inhibitory LTP. Nat Commun 5:3921.

Pribiag H, Peng H, Shah WA, Stellwagen D, Carbonetto S (2014) Dystroglycan mediates homeostatic synaptic plasticity at GABAergic synapses. Proc Natl Acad Sci U S A 111:6810-6815.

Rancillac A, Rossier J, Guille M, Tong XK, Geoffroy H, Amatore C, Arbault S, Hamel E, Cauli B (2006) Glutamatergic control of microvascular tone by distinct GABA neurons in the cerebellum. J Neurosci 26:6997-7006.

Rancz EA, Ishikawa T, Duguid I, Chadderton P, Mahon S, Hausser M (2007) High-fidelity transmission of sensory information by single cerebellar mossy fibre boutons. Nature 450:1245-1248.

Reynolds IJ, Hastings TG (1995) Glutamate induces the production of reactive oxygen species in cultured forebrain neurons following NMDA receptor activation. J Neurosci 15:3318-3327.

Rodrigo J, Springall DR, Uttenthal O, Bentura ML, Abadia-Molina F, Riveros-Moreno V, Martínez-Murillo R, Polak JM, Moncada S (1994) Localization of nitric oxide synthase in the adult rat brain. Philos Trans $\mathrm{R}$ Soc Lond B Biol Sci 345:175-221.

Sanhueza M, Lisman J (2013) The CaMKII/NMDAR complex as a molecular memory. Mol Brain 6:10

Saviane C, Silver RA (2006) Fast vesicle reloading and a large pool sustain high bandwidth transmission at a central synapse. Nature 439:983-987.

Serulle Y, Zhang S, Ninan I, Puzzo D, McCarthy M, Khatri L, Arancio O, Ziff EB (2007) A GluR1-cGKII interaction regulates AMPA receptor trafficking. Neuron 56:670-688.

Southam E, Garthwaite J (1993) The nitric oxide-cyclic GMP signalling pathway in rat brain. Neuropharmacology 32:1267-1277.

Southam E, East SJ, Garthwaite J (1991) Excitatory amino acid receptors coupled to the nitric oxide/cyclic GMP pathway in rat cerebellum during development. J Neurochem 56:2072-2081.

Steinert JR, Chernova T, Forsythe ID (2010) Nitric oxide signaling in brain function, dysfunction, and dementia. Neuroscientist 16:435-452.

Tretter V, Jacob TC, Mukherjee J, Fritschy JM, Pangalos MN, Moss SJ (2008) The clustering of $\mathrm{GABA}_{\mathrm{A}}$ receptor subtypes at inhibitory synapses is facilitated via the direct binding of receptor alpha 2 subunits to gephyrin. J Neurosci 28:1356-1365.

Tretter V, Kerschner B, Milenkovic I, Ramsden SL, Ramerstorfer J, Saiepour L, Maric HM, Moss SJ, Schindelin H, Harvey RJ, Sieghart W, Harvey K (2011) Molecular basis of the $\gamma$-aminobutyric acid A receptor $\alpha 3$ subunit interaction with the clustering protein gephyrin. J Biol Chem 286:3770237711.

Tyagarajan SK, Fritschy JM (2014) Gephyrin: a master regulator of neuronal function? Nat Rev Neurosci 15:141-156.

Vincent SR, Kimura H (1992) Histochemical mapping of nitric oxide synthase in the rat brain. Neuroscience 46:755-784.

Wang H, Bedford FK, Brandon NJ, Moss SJ, Olsen RW (1999) GABA(A)-receptor-associated protein links $\mathrm{GABA}(\mathrm{A})$ receptors and the cytoskeleton. Nature 397:69-72

Weiergräber $\mathrm{OH}$, Stangler T, Thielmann $\mathrm{Y}$, Mohrlüder J, Wiesehan K, Willbold D (2008) Ligand binding mode of GABAA receptor-associated protein. J Mol Biol 381:1320-1331.

Yee BK, Keist R, von Boehmer L, Studer R, Benke D, Hagenbuch N, Dong Y, Malenka RC, Fritschy J-M, Bluethmann H, Feldon J, Möhler H, Rudolph U (2005) A schizophrenia-related sensorimotor deficit links $\alpha 3$-containing GABAA receptors to a dopamine hyperfunction. Proc Natl Acad Sci U S A 102:17154-17159.

Zeisel A, Hochgerner H, Lönnerberg P, Johnsson A, Memic F, van der Zwan J, Haring M, Braun E, Borm LE, La Manno G, Codeluppi S, Furlan A, Lee K, Skene N, Harris KD, Hjerling-Leffler J, Arenas E, Ernfors P, Marklund U, Linnarsson S (2018) Molecular Architecture of the Mouse Nervous System. Cell 174:999-1014.e22. 